\title{
El mundo de las ciudades oscuras, de Schuiten y Peeters: una topografía de la desubicación
}

\author{
David CONTE IMBERT \\ Departamento de Humanidades: Filosofía, Lenguaje y Literatura \\ Universidad Carlos III de Madrid \\ dconte@hum.uc3m.es
}

Fecha de recepción: 20 de octubre de 2011

Fecha de aceptación: 30 de octubre de 2011

\begin{abstract}
Resumen
Las Ciudades oscuras, ciclo de novelas gráficas emprendido en 1982 por el dibujante belga François Schuiten y el guionista francés Benoît Peeters, constituyen un caso paradigmático de confluencia entre lo urbano y la ciencia ficción. Este mundo imaginario, que se enmarca dentro de la esfera del steampunk, reconfigura en sus ciudades un mosaico de los diferentes estilos arquitectónicos de nuestra civilización, rescatando a la vez su dimensión visionaria y utópica. El presente trabajo se propone esbozar un recorrido por sus principales claves estéticas y narrativas. Más que un "espejo de nuestro presente", lo que plantea el ciclo de las Ciudades oscuras es una evocación del ideal positivista y funcional que impregna el imaginario urbanístico contemporáneo. La irrupción de lo fantástico en esta perspectiva racionalista trastoca las posibilidades de armonía y equilibrio, para arrastrar a sus habitantes a una desubicación donde se proyecta la condición errante del sujeto actual.
\end{abstract}

Palabras clave: estilos arquitectónicos, urbanismo, steampunk, ucronía, posmodernidad.

Title: The Obscure Cities, by Schuiten and Peeters: a Topography of Dislocation

\section{Abstract}

The Obscure Cities graphic novels cycle, started in 1982 by the Belgian draftsman François Schuiten and the comic's writer Benoît Peeters, is a prime example of convergence between urban and science fiction. This imaginary world, which falls within the realm of steampunk, reconfigures in their cities a mosaic of different architectural styles of our civilization, rescuing both visionary and utopian dimension. This entry aims to outline a tour of its aesthetic and narrative main keys. More than a "mirror of our present", what the Obscure Cities cycle arises is an evocation of the positivist and functional ideal that pervades the contemporary urban imaginary. The inrush of the fantastic in this rationalist perspective disrupts the possibilities of harmony and balance, to drag its inhabitants to a dislocation where the wandering condition of the contemporary subject is projected.

Keywords: architectural style, urbanism, steampunk, alternate history, postmodernity. 


\section{Índice}

1. Pequeña guía de viaje por las Ciudades oscuras

2. El mosaico de las ruinas: topografía temporal de las Ciudades oscuras

Circunscribir el mundo de las Ciudades oscuras, creado por el dibujante belga François Schuiten y el escritor francés Benoît Peeters, no es tarea fácil. Se trata de un conjunto de cómics o novelas gráficas cuyo inicio arranca con la publicación de Las murallas de Samaris, en $1982^{1}$, pero cuya formalización como serie se produce con el siguiente volumen, La fiebre de Urbicanda, en 1985, y que sigue prolongándose en la actualidad. Una de las dificultades concierne al establecimiento del corpus. En efecto, si buena parte viene constituida por novelas gráficas "al uso", algunos álbumes constituyen más bien relatos o "dossiers" acompañados de ilustraciones (La ruta de Armilia, El archivista), e incluso ofrecen complementos o extrapolaciones en torno a esta realidad ficticia ${ }^{2}$. Los propios creadores han llevado a cabo conferencias, intervenciones en espacios públicos, exposiciones y, desde 1996, han quebrado el marco de la viñeta para trasladar su universo al horizonte de la red ${ }^{3}$. La multiplicidad "proteica" de las Ciudades oscuras, por retomar el adjetivo empleado por Alejo G. Steimberg (2004a: 209), dificulta la posibilidad de delimitar un conjunto cerrado que nos sirva de punto de partida ${ }^{4}$. Como apunta igualmente Philippe Marion:

Il s'agit d'un macro-récit protéiforme et polymédiatique. La matrice narrative initiale multiplie les arborescences et est elle-même affectée

${ }^{1}$ La edición en álbum data de 1983, aunque empezó a publicarse por entregas a partir del año 1982 en la célebre revista de cómic (À suivre).

2 Así, encontramos unas obras que no pueden considerarse cómics propiamente dichos, ya que ofrecen un catálogo de los medios de transporte (Enciclopedia de los medios de transporte presentes y por venir), una presentación de su periódico principal (El Eco de las Ciudades), una guía panorámica de sus rasgos geográficos, sociales, políticos, etc. (La Guía de las Ciudades), así como misceláneas (Viajes en Utopía o Las Puertas de lo Posible), cuentos cortos y relatos ilustrados. Para una delimitación aproximativa del corpus, consúltese la bibliografía final; las referencias se ofrecen por la fecha de edición o reedición del álbum. En efecto, desde hace más de un lustro, la editorial Casterman ha emprendido una reedición completa que incluye importantes modificaciones.

3 En L'aventure des images. De la bande dessinée au multimédia, Schuiten y Peeters relatan las diversas metamorfosis y etapas de su recorrido, por lo que dicho dossier constituye un excelente documento para adentrarse en las bambalinas de su laboratorio creativo. Consúltese en particular Schuiten \& Peeters (1996: 43-61 y 173-179).

4 Steimberg es posiblemente el crítico que más ha analizado el dispositivo transmediático configurado por las Ciudades oscuras. Además del citado articulo, puede consultarse el siguiente texto en línea (Steinberg 2004c):

http://www.rilune.org/dese/tesinepdf/Steinberg/Steimberg Litt\%E9ratureetinforma tique.pdf 
par les développements qu'elle a inspirés. Un grand nombre de médias sont sollicités : de la bande dessinée au site sur Internet. À la faveur des changements de médias, de nouvelles fictions s'inventent, renouvelant I'esprit de la série. À chaque nouvelle manifestation, le récepteur s'interroge moins sur les nouvelles péripéties que le récit va lui proposer que sur la manière dont le monde des cités va se trouver enrichi et solidairement infléchi.

La consistance progressive de l'univers fictionnel [...] est fondée sur le flux, la propagation programmatique. Par sédimentation du récit, par autonomisation de certains éléments, par accumulation de références et surtout d'autoréférences, le réseau - tout en croissant - gagne en cohérence interne et étoffe par là sa crédibilité et son vraisemblable. (Marion 1997: 74)

Esta multiplicidad capilar corresponde a la naturaleza de las Ciudades oscuras, en cuanto universo ficticio que aspira a presentarse como mundo virtual o posible. Los propios autores han ofrecido un mapa que no pretende sino representar la parte oeste del continente principal, dejando sistemáticamente la puerta abierta para ulteriores desarrollos o prolongaciones. Como explica La Guía de las Ciudades, semejante planeta constituye una suerte de espejo paralelo e invertido del nuestro ("un reflet décalé" ${ }^{5}$ ), imperceptible en la medida en que se halla oculto por el sol, ya que estaría situado en un polo simétricamente opuesto a nuestro planeta. Sus creadores, que aducen una función de exploradores o meros documentalistas, explican las numerosas interferencias que se vienen produciendo entre ambos planetas; justifican así la profusa intertextualidad de su obra por el carácter visionario de los autores que les sirven de inspiración ${ }^{6}$, como si éstos hubieran entrado realmente en contacto con las Ciudades oscuras a través de pasajes ocultos y abiertos hacia ese "otro mundo"7. Por ende, François Schuiten ha tenido ocasión de

5 "La manière la moins erronée de qualifier le monde des Cités obscures est sans doute de le définir comme un reflet décalé de la Terre. Sensiblement plus petit, il est invisible depuis notre planète, comme $s^{\prime}$ il était victime d'une éclipse permanente" (Schuiten \& Peeters 2002: 8).

${ }^{6}$ Algunos autores, cuya influencia desgranan como si en realidad hubieran tenido acceso al mundo de las Ciudades oscuras son escritores como Novalis, Julien Gracq, Maeterlinck, René Daumal (Le Mont Analogue), Franz Kafka, Walter Benjamin, Italo Calvino, Ismaël Kadaré, Jorge Luis Borges o Adolfo Bioy Casares. Pero encontramos también filósofos de la tradición esotérica, como Swedenborg o John Dunne (el personaje de Elías en La Torre está inspirado en Paracelso); dibujantes, como Piranese o Gustave Doré, o arquitectos como el singular Joseph Polaert. Las referencias o guiños intertextuales son a decir verdad innumerables, y forman parte intrínseca de la dinámica narrativa del ciclo.

7 "La nature exacte des relations entre les deux mondes demeure des plus mystérieuses : il existe assurément des passerelles, mais leur nature exacte reste difficile à définir. Courbure de l'espace, faille temporelle, enchâssement d'univers : toutes ces hypothèses sont trop grossières pour rendre compte de manière 
plasmar sus visiones de ese "otro mundo" en el nuestro con varias remodelaciones arquitectónicas, por ejemplo en las estaciones de metro Arts et Métiers, en París, y la de Porte de Hal, en Bruselas.

Podríamos afirmar que las Ciudades oscuras representan un mundo ficticio que se nutre de innumerables referencias a nuestra realidad, hasta el punto de constituir una especie de mosaico o patchwork lúdico de nuestro planeta. En este sentido, su imaginario constituye un reciclaje "posmoderno" de diversas corrientes artísticas, culturales y urbanísticas de nuestra tradición, pero a su vez dicho reflejo acaba actuando en el mundo que imita o parodia no solamente a través de su capacidad proyectiva, sino insertándose en cuanto creación cultural con valor epistemológico e incluso performativo ${ }^{8}$.

Nuestro análisis tomará únicamente en cuenta un aspecto de este entrelazamiento poliédrico, a saber la visión de la ciudad que de allí se desprende y que encarna su eje temático central. Dicha elección puede parecer evidente, pero cabe recalcar una serie de diferencias y matices en la configuración de lo urbano, como hilo conductor que garantiza la coherencia del ciclo.

Por un lado, el modelo de narración gráfica otorga en sus viñetas una importancia decisiva a los elementos arquitectónicos, que dejan de constituir un simple decorado para la evolución y el encuadre de la acción, convirtiéndose en muchos casos en motivo central de su dibujo. Los personajes que aparecen a lo largo de la serie se ven empequeñecidos por los monumentos que les circundan, y muchos diálogos parecen emerger directamente de los edificios que habitan. El trazo de François Schuiten denota una importante formación arquitectónica, oficio que de hecho ejerció su padre, y al que se dedica actualmente su propio hermano ${ }^{9}$. Las Ciudades oscuras

satisfaisante des liens unissant les deux planètes" (Schuiten \& Peeters 2002: 9). La Guía de las Ciudades enumera una lista de tales pasajes o pasarelas (Schuiten \& Peeters 2002: 52-63), que corresponden a los lugares predilectos de sus autores (como el Palacio de Justicia de Joseph Polaert en Bruselas, por ejemplo), a los que añaden sus propias intervenciones expositivas o arquitectónicas.

${ }^{8}$ Esta idea viene desarrollada en un artículo de Alejandro Riberi donde, en una lectura conjunta de las Ciudades oscuras y el cuento de Borges "Tlön, Uqbar, Orbis, Tertius", reivindica el poder epistémico y performativo de los mundos posibles: "Fictions constitute cognitive instruments. They advance an understanding of the empirical world in as much as it is by means of fictional arrangements, chiefly the raising of certain attributes of the real and the suppressing of others, that we permanently subsume the unknown to the known. This is plainly the case of Concepts and categories where only the common elements are highlighted while the differences are suppressed. Fictions such as categories and general ideas intervene in any assertion that we make about reality" (Riberi 2010: 3).

9 El padre de François, Robert Schuiten, fue un conocido arquitecto de Bruselas durante las décadas de los 50 y 60 . El caso del hermano Luc es sin duda más interesante, ya que su trabajo se inscribe dentro de una práctica de la arquitectura 
se nos presentan en este sentido como un universo narrativo donde las urbes ejercen un papel protagonista y encauzan las peripecias de la trama.

Sin embargo, este carácter central de la urbe ha ido perdiendo importancia a medida que la propia serie ha ido creciendo y madurando. Podríamos fijar dos etapas diferenciadas. La primera agruparía las cinco primeras entregas: Las murallas de Samaris (1983), La fiebre de Urbicanda (1985), La torre (1987), La ruta de Armilia (1988) y Brüssel (1992), añadiendo también el peculiar álbum de El archivista (1987), que marca una suerte de clave de bóveda para el conjunto ${ }^{10}$. Los propios títulos anuncian que la ciudad ocupa allí una función decisiva, y la trama se articula en torno a la peripecia misma de la urbe ${ }^{11}$. En esa fase, el dibujo de los personajes resulta mucho más imperfecto que el de los edificios, y sus propios rasgos se ven impregnados por la marcada geometría de los trazos arquitectónicos.

Mas a partir de La niña inclinada (1996), el foco de la acción se desplaza sobre los propios habitantes. La trama recalca una anomalía

que podríamos calificar de visionaria, conjugándose con la ecología en una nueva versión del organicismo de Frank Lloyd Wright, y desarrollando el concepto de "arquiborescencia" o ciudad vegetal, donde los propios edificios se conciben a la manera de plantas (puede consultarse al respecto la siguiente página web: http://www.archiborescence.net). Por muchos aspectos, la práctica de Luc se entrecruza con la imaginación de François, lo cual, más allá de ocasionales colaboraciones, contribuye a este vaivén entre realidad y ficción -donde la ficción opera como una suerte de criterio o construcción de la propia realidad- que caracteriza la poética de las Ciudades oscuras.

${ }^{10}$ El archivista, que no puede considerarse un relato ilustrado en sentido estricto, supone una piedra angular en la concepción global de la serie. Nos presenta la figura de Isidore Louis, encargado de la sección de mitos y leyendas en el Instituto Central de los Archivos, que recopila una serie de documentos referidos a la misteriosa existencia de un universo paralelo llamado las Ciudades oscuras. A la vez que traza un mapa que apunta a futuros desarrollos, plantea el estatus de este mundo ficticio en sus enigmáticas conexiones o "pasarelas" con respecto al nuestro. El final invierte las tornas, ya que tras ser expulsado del Instituto, Isidore Louis descubre un último legajo donde él mismo figura como personaje legendario de dicha realidad paralela.

${ }^{11}$ Esto supone una importante modificación con respecto al lenguaje habitual del cómic, y en particular con respecto al uso del decorado como trasfondo de la viñeta, tal y como lo plantea, por ejemplo, Scott McCloud (2007: 42-43) en su excelente recorrido por el código semiótico del género. Aunque no vayamos a adentrarnos de forma pormenorizada en la peculiaridad de dicho código, es evidente que la poética de las Ciudades oscuras parte del formato narrativo de la novela gráfica. Para tal acercamiento, puede consultarse el artículo de Laurent Gerbier sobre las modificaciones que introduce el uso de lo fantástico en el montaje tradicional del cómic, en particular con respecto al uso de la "clausura"; como explica Gerbier, la reconfiguración del juego entre continuidad y discontinuidad convierte el dibujo mismo en motor narrativo del imaginario fantástico (Gerbier 2003: 24-25). 
que afecta a determinados personajes (y ya no tanto a la ciudad misma), y que les transforma hasta alcanzar una suerte de nueva lucidez, sobreponiéndose a la marginación social acarreada en un principio (La niña inclinada, por ejemplo, o La sombra de un hombre, en 1999). Asimismo, el marco urbano se desborda e involucra una problemática social o humana en su conjunto, como es el caso de $L a$ frontera invisible (2002 y 2004), que plantea la cuestión de la representación cartográfica con respecto a la falsificación de las fronteras que pretende imponer la Sodrovno-Voldachie en su afán de expansión totalitaria. También en el último hasta la fecha, Souvenirs de l'éternel présent ${ }^{12}$, encontramos una sociedad sumida en el olvido del pasado y marcada por su renuncia al progreso, donde la aventura de un niño por descubrir todo lo que se le oculta constituye la peripecia central de la trama. Por supuesto, el marco urbano sigue en extremo presente, pero podríamos decir que actúa bajo la forma de un decorado más clásico dentro del lenguaje habitual del cómic. Del mismo modo, el trazo de los personajes ha ido evolucionando, y si al principio, como es el caso de Eugen Robick, en La fiebre de Urbicanda, o de Franz Bauer en Las murallas de Samaris, la fuerte geometrización de sus rasgos tendía a cierta rigidez, a partir de La torre $^{13}$ los perfiles fueron dotándose de mayor expresividad y adquiriendo mayor calidad gráfica.

A pesar de todo, y acorde con las lógicas metamorfosis creativas de un universo que se va enriqueciendo en cada nueva entrega, la ciudad sigue constituyendo el eje que unifica ese mundo paralelo, y que proporciona las claves de su coherencia poética. Por ello, intentaremos llevar a cabo un análisis de este complejo tejido urbano, recalcando sus rasgos comunes así como sus diferencias particulares. Comenzaremos por trazar un panorama general de sus hitos urbanísticos, rastreando en la medida de lo posible sus múltiples influencias y referencias, que aglutinan una suerte de reflexiva proyección sobre la condición urbana en la posmodernidad. Convendrá examinar en una segunda parte de qué modo dicho modelo se enmarca dentro del género de la ciencia ficción, ya que sus claves estéticas, a pesar de ciertas distorsiones, obedecen a una

12 La edición de 2009 supone una reescritura en forma de cómic de un relato ilustrado publicado en 1993, llevado a cabo paralelamente al rodaje de una película con Raoul Servais titulada Taxandria (1994), que los propios autores consideran una experiencia fallida por culpa de los avatares de la producción (Schuiten \& Peeters 2009: 66-77).

${ }^{13}$ Resulta curioso que semejante transformación proceda de una figura real, puesto que el personaje de La torre, Giovanni Battista -cuyo nombre es un homenaje a Piranese-, reproduce los rasgos de Orson Welles en su madurez. Los autores, fascinados por su caracterización del Falstaff de Shakespeare, solicitaron emplearlo como modelo para su protagonista, a lo que amablemente se prestó el veterano actor y director durante largas sesiones de pose. 
temporalidad ucrónica bastante próxima a nuestra propia realidad, e incluso situada en un pasado característico de la corriente del steampunk. Por ello, la prodigiosa creatividad visual y conceptual de este paisaje nos llevará a desentrañar los fundamentos poéticos de su diversidad, comprendiendo de qué modo semejante fantasía supone una meditación sobre las quimeras y aberraciones de la modernidad, donde las metonimias de lo urbano reflejan la desubicación del individuo envuelto en sus propios espejismos.

\section{Pequeña guía de viaje por las Ciudades oscuras}

Para esbozar un breve panorama del planeta de las Ciudades oscuras, conviene apuntar primero algunos trazos acerca de su geografía y su evolución histórica y política. Por el momento, la cuasi totalidad del ciclo se ubica en el oeste del macro continente planetario que figura en el siguiente mapa (figura 1 ):

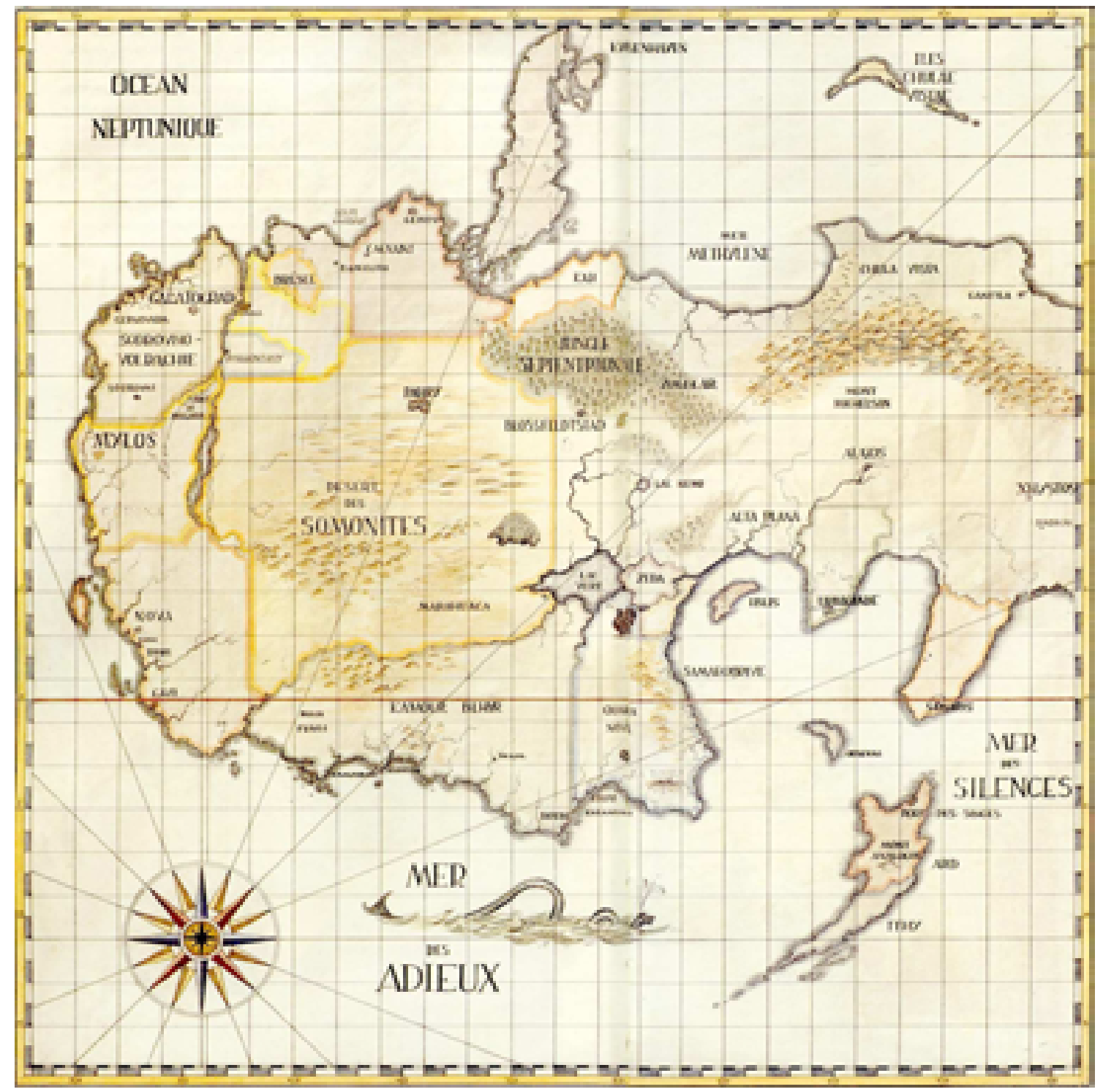

Figura 1. La parte oeste del continente de las Ciudades oscuras. 
Si exceptuamos la ciudad de Armilia, situada en el polo norte, y que La ruta de Armilia representa como un gran mecanismo esférico de relojería que rige y controla el tiempo del orbe, allí se encuentran las principales ciudades que protagonizan o enmarcan los relatos sucesivos. Su marco cronológico oscila entre el año 450 de una era que arrancaría con la construcción de una gigantesca Torre, y alcanza el año 784, donde se producen los misteriosos sucesos referidos en Teoría del grano de arena.

El año 450 marca el inicio del viaje de Giovanni Battista, encargado del mantenimiento de uno de los sectores de la torre que, cansado de esperar la visita del inspector, emprende un descenso para pedir cuentas a los gobernantes por su desidia. La tonalidad kafkiana del relato, donde Giovanni vaga por una mole de piedra inabarcable en busca de una autoridad inexistente u oculta, se mezcla con el mito de fundación que sustenta la diversidad de las Ciudades oscuras, a saber la torre de Babel. El cuadro de Bruegel constituye aquí la fuente de inspiración principal, pero el entrelazamiento de bóvedas y escaleras también se nutre de los grabados de Piranese en sus Invenzioni capriciosi di carcere ${ }^{14}$. Al final del relato, Giovanni Battista llega hasta los cimientos de la Torre, tras haber contemplado el vacío absurdo de su cima, y sale a la superficie, donde se ve inmerso en una guerra con tintes de campaña napoleónica. El sueño de unidad desemboca así en el conflicto y en la pluralidad de las distintas ciudades.

En el origen de su eclosión, encontramos a continuación la hegemonía de Pâhry (a partir del año 571), deformación ortográfica de la "capital del siglo XIX", en palabras de Walter Benjamin. Pâhry brinda el modelo de desarrollo urbano que procurarán imitar las otras ciudades, como así ha podido suceder en gran parte de las metrópolis europeas a lo largo de los dos últimos siglos. No obstante, la otra urbe que más alusiones contiene a una ciudad real, como es el caso de Brüssel, imita más bien en su plan de desarrollo el skyline de Manhattan, del mismo modo que los rascacielos de Nueva York tomaron el relevo de las perspectivas haussmanianas como influencia urbanística global. Junto a Brüssel y Pâhry, Schuiten y Peeters introducen otras ciudades que encarnan trasuntos de lugares reales, a caballo entre la imitación toponímica y la reproducción

14 En la reedición de 2008, los autores especifican las diversas fuentes que constituyen el entramado intertextual de La Torre. En el cuadro de Bruegel, tal y como apuntan, el mito se condensa en una imagen que contiene una pluralidad inagotable de historias, como si la dispersión narrativa de las ciudades oscuras encontrara en esa fuente icónica toda su potencialidad "babélica", por así decirlo: "Le tableau le plus connu de Bruegel a été notre premier générateur: il condense admirablemente ce mythe en une image qui paraît inépuisable. On a le sentiment, en regardant de près cette peinture, qu'elle pourrait constituer le point de départ d'une infinité de récits" (Schuiten \& Peeters 2008: 103). 
arquitectónica. Así encontramos Bayreuth, donde los habitantes se entregan al ritual operístico; Københaven, situada en una península casi idéntica a Dinamarca; Brazil, imagen de la Brasilia de Lucio Costa y Oscar Niemeyer; pero también Genova, Zanzibor, e incluso Porrentruy, nombre de un pequeño burgo del Jura suizo donde nuestros autores impartieron una charla sobre su obra. Por último, dentro del amplio elenco de nombres, el Monte Michelson parece apuntar al Mont Saint-Michel, la isla de Orsenna corresponde a la ciudad de donde es oriundo el protagonista de Le rivage des Syrtes, de Julien Gracq, y el bosque de Megara podría aludir a una de las Erinías y antigua ciudad griega situada en el golfo de Egina, aunque sospecho que la referencia pudiera deberse al exotismo cartaginés de Salambó, de Gustave Flaubert ${ }^{15}$.

Sin embargo, si exceptuamos el caso de Brüssel, sobre el cual tendremos ocasión de volver, las principales ciudades donde se desarrollan los relatos esbozan universos ficticios que poca relación mantienen con urbes realmente existentes. Mas ello no se debe a las posibles modificaciones que los autores introducen en la configuración de las calles o edificios, sino a varios factores que conviene desgranar a continuación.

En efecto, muchas de las Ciudades oscuras encarnan una suerte de modelo puro de urbanismo, bien sea por la arquitectura que allí se concibe como por la unidad funcional que define sus rasgos y su carácter. De alguna forma, Schuiten y Peeters han plasmado en sus novelas gráficas los sueños y quimeras de las grandes corrientes arquitectónicas de la modernidad. Aunque la huella de estas concepciones haya quedado limitada a edificios singulares, si acaso al estilo o patrón de cierta época, muchos de los arquitectos que han marcado nuestro tiempo han soñado con una reorganización global de la sociedad urbana.

Obviamente, algunos de estos proyectos sí han tenido lugar a gran escala, desde la Brasilia de Costa y Niemeyer hasta la edificación de la nueva capital del Punjab, Chandīgarh, por parte de Le Corbusier. Otros proyectos han supuesto una transformación radical del tejido urbano, citando desde el Eixample de Ildefonso Cerdà o los grandes bulevares de Haussmann hasta los proyectos de "Garden Cities" de Ebenezer Howard y Louis de Soissons. Las ciudades de "nueva planta" no han sido patrimonio exclusivo de regímenes totalitarios, como la URSS y su área de influencia, que tuvieron la capacidad de modelar las formas de vida a través de sus concepciones urbanas, sino que de alguna forma han marcado el crecimiento de casi todas nuestras ciudades. Así, la proliferación de

15 El topónimo aparece de hecho en la primera frase del libro: "Sucedía en Megara, arrabal de Cartago, en los jardines de Amílcar" (Flaubert 1999: 41). 
suburbios idénticos y homogéneos traduce esa antigua visión funcionalista de la Carta de Atenas (1933), donde los espacios habían de dividirse y repartirse siguiendo las cuatro actividades humanas (trabajar, vivir, circular, distraerse). Si, a lo largo de la historia, lo urbano siempre ha reflejado lo social, la vertiente utópica decimonónica, desde los falansterios de Fourier hasta la New Harmony del empresario Robert Owen, alimentó buena parte de las más delirantes quimeras del urbanismo moderno. En este sentido, los planos de Albert Speer para el nuevo Berlín del Reich nacionalsocialista no quedan lejos del Plan Voisin de Le Corbusier, donde únicamente subsistiría la catedral de Notre Dame en un París devastado por cuatro gigantescos rascacielos, por no hablar de su proyecto para la "Ciudad de 3 millones de habitantes" ${ }^{16}$.

Como tendremos ocasión de analizar, la poética de las Ciudades oscuras se nutre de las ilusiones de progreso de la modernidad, con sus luces y sombras, pero sobre todo plantea una suerte de especialización funcional o estética. Tenemos, por ejemplo, el caso de Mylos, que representa el paradigma de ciudad industrial decimonónica, con sus torres de ladrillo y sus fábricas humeantes. Frente a Mylos, la ciudad de Alaxis, mezcla de edad media y renacimiento italiano, con palacios y canales venecianos que alternan con cúpulas florentinas, encarna la ciudad turística por excelencia, destinada al ocio y el disfrute, con su parque de atracciones como telaraña ramificada por innumerables mansiones y estancias. EI contraste entre ambas rige el inicio de La niña inclinada, cuando la familia Von Rathen, ricos industriales de Mylos caracterizados por su seriedad y espíritu calvinista, pasa unas vacaciones en Alaxis. La única que parece divertirse en tal ambiente es Mary, que arrastra a sus progenitores y hermano a una laberíntica montaña rusa, de la que saldrá "torcida"17. Otro modelo de "especialización" aparece en

16 Pueden verse los diseños y comentarios para ambos proyectos en el catálogo publicado por el Centre Georges Pompidou con ocasión de una exposición en torno a la ciudad, que contrapone cuadros y representaciones artísticas frente a proyectos arquitectónicos, desde 1870 hasta 1993 (Dethier \& Guiheux 1994: 290298 y 357-358). Además del citado catálogo, nuestras referencias proceden de las breves introducciones al urbanismo de Merlin (1991) y Blanquart (1998), así como de la extensa historia de Michel Ragon (2010) y la antología de Françoise Choay (1979).

17 Esta misteriosa inclinación queda explicada por la atracción gravitatoria de un misterioso planeta hasta el que viajará Mary en compañía del inventor y científico por excelencia del mundo oscuro: Axel Wappendorf. Se trata del álbum que mayor juego introduce entre "realidad" y "ficción" (entre nuestro planeta y aquella dimensión paralela), ya que Mary se encuentra allí con un pintor llamado Auguste Desombres, cuya historia se intercala en la trama principal por medio de un relato fotográfico. En dicho planeta el señor Wappendorf conoce también a Julio Verne, en un divertido guiño al método de viaje empleado: un misil disparado por un gigantesco cañón. 
Calvani, la ciudad de los invernaderos, donde una exposición interurbana, evidente trasunto de las exposiciones universales de nuestro mundo, desencadenó una profunda transformación, al proliferar los grandes palacios de cristal característicos de la arquitectura industrial, dedicados al cultivo de las más exóticas plantas en "una atmósfera pesada y húmeda"18.

No obstante, salvando el caso algo particular de La Torre, los dos conjuntos visualmente más homogéneos aparecen en los dos primeros álbumes, donde la ciudad se erige en nudo y enigma central del relato. En primer lugar, Las murallas de Samaris arranca en la ciudad de Xhystos, donde el Consejo que gobierna la ciudad encomienda a Franz Bauer una misión en Samaris, en la que están teniendo lugar extraños sucesos y han desaparecido varios viajeros previamente comisionados. Al cabo de un recorrido extenuante, Franz llega a Samaris y, tras encontrar una habitación en lo que se le antoja el único albergue del lugar, decide emprender sus pesquisas. Mas nada anómalo parece suceder, sino cierta incomodidad que va adueñándose de Franz a lo largo de sus paseos. En efecto, la ciudad cambia a medida que la recorre, los habitantes se comportan como soñolientos autómatas, le sorprende la total ausencia de niños, y la mujer con la que intenta entablar una relación, Carla, se muestra esquiva y hermética en su trato.

Franz acaba descubriendo el secreto de Samaris; se trata de una ciudad concebida como un gigantesco decorado destinado a atrapar a los imprudentes viajeros que allí se aventuran, actuando como la flor carnívora que le sirve de emblema (la drosera). El conjunto no es más que un "trompe-I'oeil", un inmenso simulacro de cartón piedra gobernado por una maquinaria hidráulica que mueve las fachadas por medio de vigas y poleas (figura 2). Franz consigue escapar y volver a Xhystos, pero todo ha cambiado como si hubiera trascurrido una vida entera. Ya no conoce a nadie y nadie le reconoce; tiene que aguantar una espera interminable para que alguien del Consejo se digne a recibirle. Al ser finalmente autorizado a pasar, se da cuenta de que los propios miembros del Consejo son también figuras de cartón piedra. Sin conseguir desligar la realidad

\footnotetext{
18 Véase lo que nos dice Isidore Louis, el archivista: "Le projet n'avait été d'abord que celui d'une exposition temporaire regroupant les essences les plus rares. Mais l'engouement fut tel que les pavillons se multiplièrent au cours des mois suivants, les Calvaniens délaissant leurs lourdes demeures au profit des palais de cristal. Sous l'impulsion d'un ancien concessionnaire des boues et vidanges reconverti dans l'amour des fleurs, la ville entière se transformait en serre. [...] Certains affirment que ce bel enthousiasme retomba presque aussi vite qu'il s'était imposé. Des maladies étranges se seraient développées à la faveur de cette atmosphère lourde et moite, les serres seraient tombées en désuétude, et l'ingrate nature calvanienne aurait repris ses droits" (Schuiten \& Peeters 2009: 28).
} 
del simulacro, Franz regresa a Samaris al tomar conciencia de que allí se encuentran sus raíces.

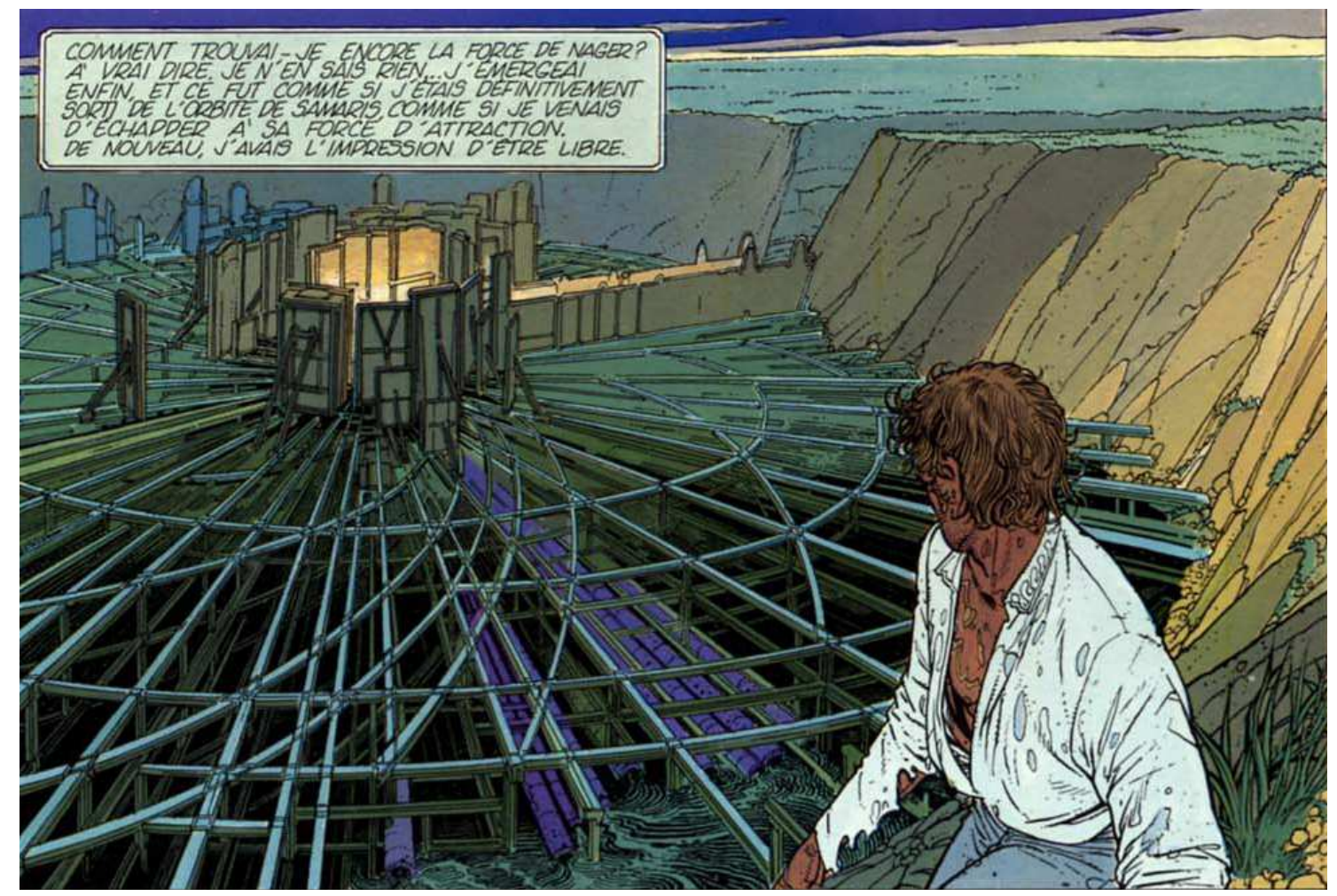

Figura 2. Franz Bauer contempla el simulacro de la ciudad de Samaris.

Este juego semiótico en torno a la naturaleza de lo urbano y, en último término, al funcionamiento de su propia narración visual ${ }^{19}$, ofrece un contraste de estilos entre ambas ciudades que las dota de coherencia y personalidad propia. No es de extrañar que, para semejante juego de ilusiones, Samaris recurra a los motivos de la arquitectura barroca -aunque mezclados con influjos orientales y renacentistas-, época en la que el espectáculo de los decorados y fachadas sostenía la ideología estética de la contrarreforma. Por el contrario, la ciudad de Xhystos se nos presenta como la quintaesencia del Art Nouveau o modernismo, con sus cúpulas de cristal entreveradas de hierro, material omnipresente en las construcciones de finales del XIX, $y$ sus adornos florales en redondeadas curvas (figura 3 ). Xhystos supone también un homenaje

19 Debido a esta dimensión semiótica (la ciudad se convierte en signo o emblema de un significado de orden simbólico), Las murallas de Samaris nos recuerda la perspectiva de Italo Calvino en su libro Las ciudades invisibles, otra evidente fuente de inspiración para Schuiten y Peeters: del mismo modo que en las descripciones de Marco Polo a Kublai Khan, la ciudad únicamente cobra su sentido y realidad a través de la mirada del viajero. 
a Víctor Horta, el arquitecto que Schuiten y Peeters tal vez más admiren, y que se integra así en el ciclo desde sus inicios ${ }^{20}$.

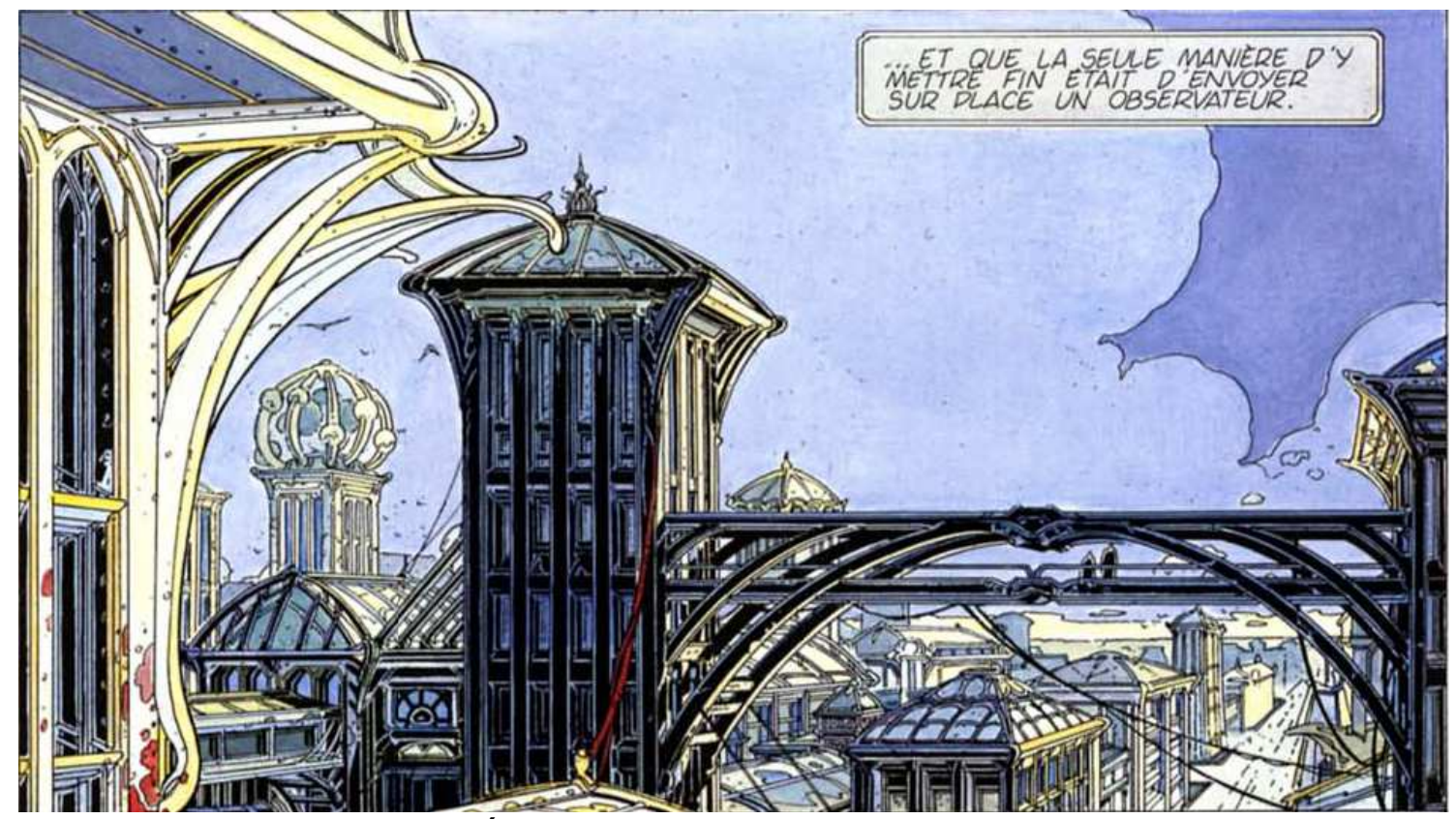

Figura 3. La estética Art Nouveau de la ciudad de Xhystos.

En efecto, el influjo de Horta y del Art Nouveau reaparece en varias ocasiones, tanto en el álbum de Brüssel, donde nuestros autores no se privan de criticar los numerosos destrozos de la Bruselas real, como en La sombra de un hombre, donde dicho estilo se orienta hacia un modernismo de corte más organicista y en ocasiones próximo al estilo internacional ${ }^{21}$.

20 Como explican en La guía de las ciudades, los habitantes del mundo oscuro toman conocimiento de las obras del arquitecto belga Víctor Horta a través de esas misteriosas pasarelas por las que ambas realidades se entrecruzan. Horta, por quien Schuiten y Peeters sienten auténtica devoción, se convierte así en una de sus principales influencias visuales. La ciudad de Xhystos no constituye aquí el único ejemplo, ya que en su Brüssel imaginaria se encuentra el "memorial" Horta. El álbum empieza de hecho con algunas referencias urbanísticas a la Bruselas real, donde lamentan el atropello que supuso la destrucción de la Casa del Pueblo, edificada por Horta en 1896 para el Partido Comunista, y que el municipio derribó en 1966 (Schuiten \& Peeters 1996: 147 y 159; Schuiten \& Peeters 1992: 7-8).

${ }^{21}$ Aunque en La sombra de un hombre (1999) la ciudad suponga más un decorado o soporte para la trama que una presencia de primer plano, su concepción resulta en extremo interesante, ya que parece retomar esos influjos iniciales del Art Nouveau, pero acentuando esa faceta "orgánica" peculiar del modernismo español y, sobre todo, catalán. La configuración de los edificios como plantas o vegetales, donde cabría identificar un paralelismo con los planteamientos de Luc Schuiten, se junta asimismo con el llamado "estilo internacional", que marcaría la evolución del Art Nouveau hacia la arquitectura "high-tec", presente en numerosos rascacielos americanos. 
Si el Art Nouveau caracteriza el primer volumen de la serie, el Art Déco tomará el relevo en el segundo, impregnando el diseño arquitectónico de La fiebre de Urbicanda (1985). Allí aparece otro de los personajes centrales del ciclo, Eugen Robick, urbatecto al que la Comisión que gobierna la ciudad ha encargado la remodelación de la orilla sur, y que lucha con denuedo para proseguir su trabajo en la parte norte ${ }^{22}$. Como puede verse en la siguiente ilustración (figura 4), la separación entre ambas orillas contrapone una ciudad geométrica de avenidas rectas y perspectivas monumentales al vericueto de callejuelas enmarañadas propio de la ciudad medieval. Los valores que propugna Eugen Robick rechazan el "arabesco" del Art Nouveau para defender una armonía rectilínea y severa, partidaria de las simetrías depuradas del clasicismo (o, más exactamente, de la relectura moderna del clasicismo).

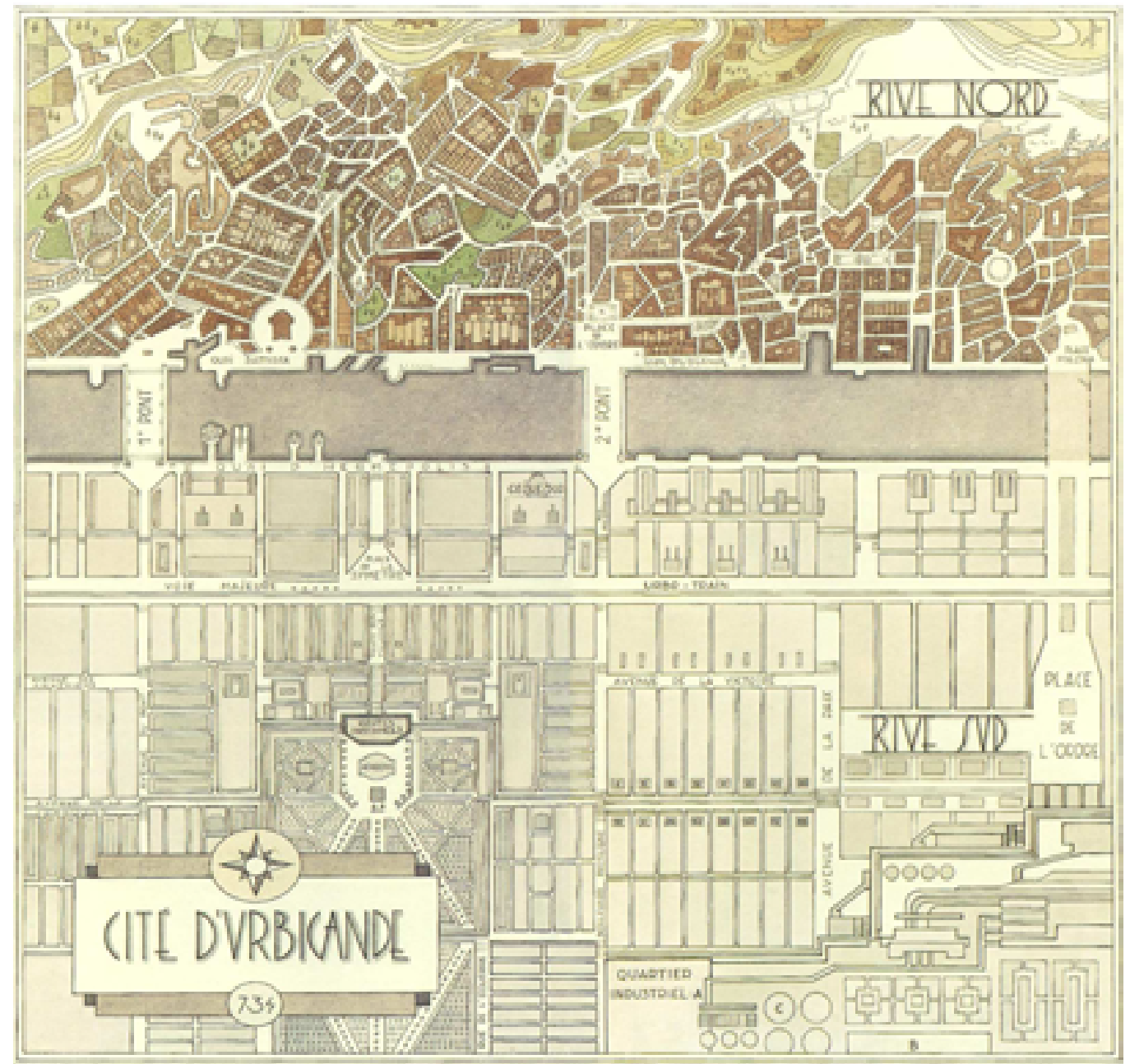

Figura 4. El plano de la ciudad de Urbicanda con el contraste entre sus dos orillas.

22 Un estudio muy detallado sobre La fiebre de Urbicanda se encuentra en el siguiente artículo de Steimberg (2004b):

http://www.rilune.org/dese/tesinepdf/Steinberg/Steinberg Artfantastique.pdf 
La ciudad de Urbicanda ofrece una escenografía muy similar a las que filma Leni Riefenstahl en su "Trilogía de Nüremberg", particularmente durante la celebración del congreso del Partido Nacionalsocialista en Triumph des Willens (1934). Esta dimensión totalitaria del gobierno de Urbicanda queda patente cuando la Comisión de Altas Instancias rechaza el proyecto de Robick para un tercer puente entre ambas orillas, que permitiría remediar la imperfecta simetría del conjunto. Para los miembros de la Comisión, lo principal es mantener el control de la orilla norte impidiendo un tránsito excesivamente fácil hacia el sur. La semiótica de Urbicanda se articula en torno al conflicto entre orden y caos, donde lo fundamental radica en evitar a toda costa la contaminación entre ambos.

Como podría adivinarse, la trama se centra así en el caos que va a adueñarse de la ciudad a raíz de la aparición de un pequeño cubo con aristas puntiagudas, que comenzará a crecer y multiplicarse de forma exponencial, invadiendo el tejido urbano con una gigantesca red geométrica (en francés, "le réseau") que hace saltar por los aires la frágil separación entre el mundo del orden y el mundo del desorden. Tras el pánico y la inquietud que se apoderan al inicio de la población, y que provoca la caída de la Comisión, los travesaños entre las orillas posibilitan el surgimiento de nuevas formas de vida (garitas y oficios se instalan en torno a la red), y sobre todo de una sociabilidad que rompe con el rígido control previo ${ }^{23}$. Incluso Robick acepta, a instancias de Sophie, adentrarse en la parte norte, descubriendo un insólito y alegre bullicio de mercadillos y tabernas que, por culpa de sus prejuicios, apenas logra apreciar. Para Robick, el problema sigue radicando en la simetría del conjunto; cuando los obreros trajeron el pequeño cubo a su despacho, su amigo Tomás estuvo jugando con él y lo depositó a caballo sobre una pila de papeles. Todo el crecimiento posterior arrastró el desequilibrio inicial provocado por este gesto accidental, creando sobre la ciudad una inmensa pirámide torcida (figura 5).

23 Como en la ciudad de Ersilia (Calvino 1983: 88), esta nueva arquitectura orgánica supone una metáfora de las relaciones humanas, como si cada travesaño propiciara un vector para encuentros e intercambios: "En Ersilia, para establecer las relaciones que rigen la vida de la ciudad, los habitantes tienden hilos entre los ángulos de las casas, blancos o negros o grises o blanquinegros según indiquen relaciones de parentesco, intercambio, autoridad, representación. Cuando los hilos son tantos que ya no se puede pasar entre medio, los habitantes se van: se desmontan las casas; quedan sólo los hilos y los sostenes de los hilos [...] telaraña de relaciones intrincadas que buscan una forma". 


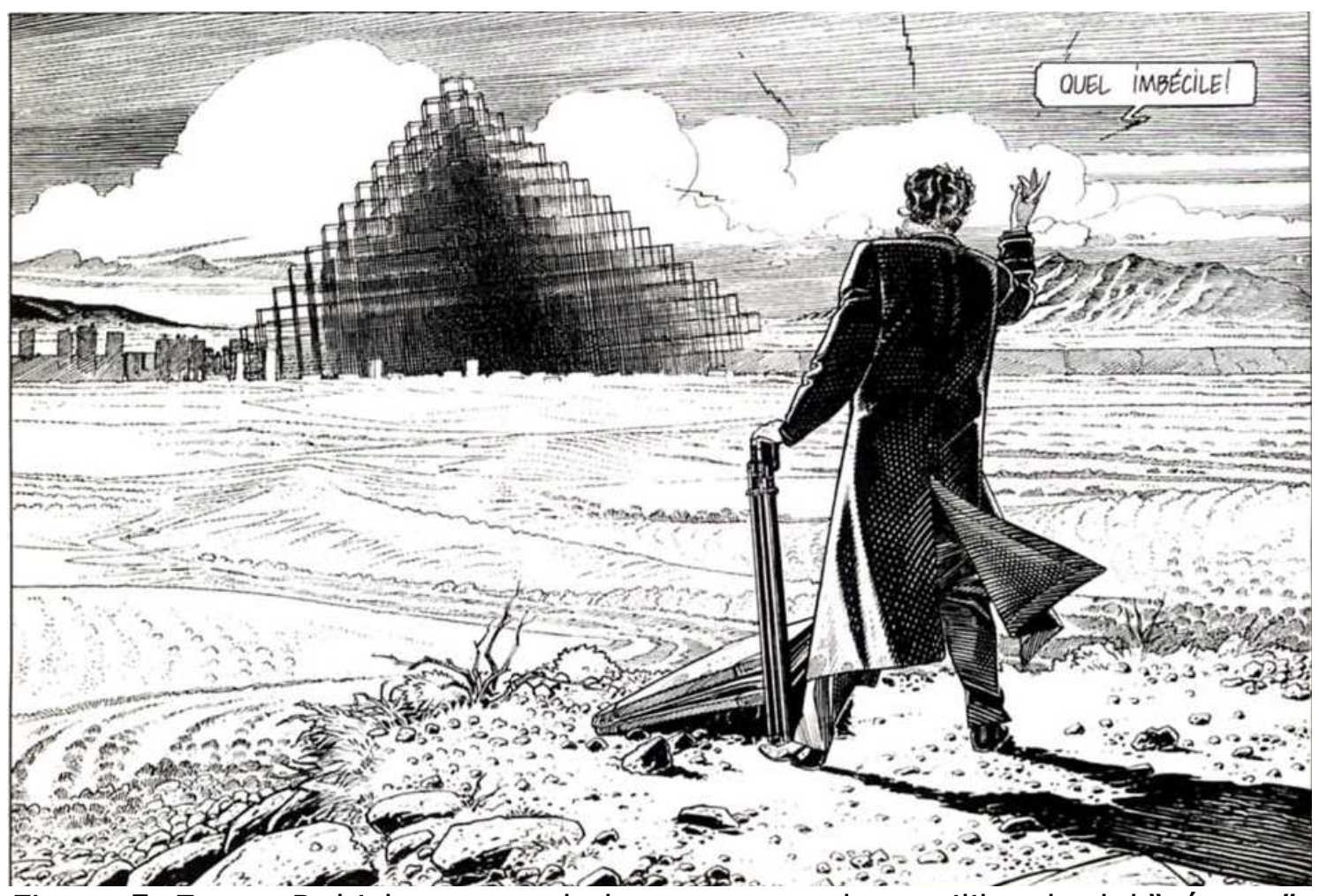

Figura 5. Eugen Robick contempla la estructura desequilibrada del "réseau".

Tras haberse estabilizado durante el período invernal, el "réseau" reemprende su crecimiento con la llegada del deshielo, provocando numerosos destrozos y rebasando los límites de la ciudad hasta alcanzar, se supone, los espacios infinitos. Esta desaparición acarrea en los habitantes la nostalgia por aquel tiempo caótico y feliz. El cómic finaliza con un proyecto faraónico de reconstrucción de la red, al que se opone Robick. Para el, semejantes obras ignoran el funcionamiento mismo del cubo. En efecto, paralelamente a la contraposición entre orden y caos, su naturaleza revela de nuevo la diferencia entre una ciudad pétrea y deshumanizada y el espontáneo crecimiento de un organismo vivo. Aunque el enigma que lo envuelve no acabe nunca de aclararse, las connotaciones y metáforas que lo ilustran pertenecen al ámbito de lo vegetal. Si el cubo es una especie de planta (el ciclo de su "florecimiento" parece atestiguarlo), su crecimiento al mismo tiempo geométrico y orgánico encarnaría ese nexo de unión entre la vertiente vegetal del Art Nouveau y las simetrías depuradas y futuristas del Art Déco.

A mi juicio, semejante ambivalencia constituye uno de los leitmotiv visuales y temáticos de las Ciudades oscuras, articulado en torno a dos estilos fundamentales de la arquitectura moderna, pero que sobre todo conlleva una dicotomía en cuanto a valores y formas de vida. Las peripecias de Schuiten y Peeters suponen una celebración del imaginario urbanístico, en cuanto ideal de las sociedades humanas, que en numerosas ocasiones acaba trocándose 
en pesadillas que arrastran a los individuos a la pérdida de su propia identidad. En este sentido, la perspectiva espacio-temporal en la que se ubican actúa como un espejo proyectivo que trataremos de situar en su marco genérico, a saber las ucronías de la ciencia ficción.

\section{El mosaico de las ruinas: topografía temporal de las Ciudades oscuras}

Sin duda, la representación gráfica de las diferentes ciudades ofrece modelos imaginarios o fantásticos que poca relación guardan con el nuestro. Las visiones de Xhystos, Samaris, Urbicanda 0 Blossfeldtstad ${ }^{24}$ pertenecen en mayor medida a las fantasías de un arquitecto que a la realidad urbana contemporánea. De inmediato el dibujo nos transporta a mundos soñados, alejados de cualquier pretensión "realista": nos hallamos situados en otra dimensión, con una cronología diferente y una serie de códigos propios, lo que a priori nos remitiría al ámbito de la ciencia ficción. Al mismo tiempo, las Ciudades oscuras muestran unos vínculos de parentesco que las aproximan y las engarzan con nuestro presente. Por supuesto, semejante parentesco no quiebra su adscripción genérica; contrariamente a la fantasy, e incluso a la literatura fantástica, éstas no plantean ningún tipo de universo mágico, y los fenómenos inexplicables siempre son abordados desde una perspectiva racional que nunca bascula en la mera aceptación de lo sobrenatural. Si, como se ha afirmado muchas veces, la ciencia ficción actúa como "espejo del presente", ¿cuál sería entonces, en el caso que nos ocupa, la posición y el ángulo de tal espejo? ¿Desde dónde proyecta su reflejo $y$, sobre todo, qué imagen o cuadro de nosotros mismos permite narrar e iluminar?

En primer lugar, la totalidad del ciclo podría acotarse en la temporalidad de lo que se conoce como el steampunk, aunque convendría matizar esta afirmación. Es cierto que gran parte evoca una estética retrofuturista, donde los trajes nos recuerdan al vestuario de la época victoriana o de la Belle Époque, sus medios de

${ }^{24}$ Ciudad donde se desarrollan las aventuras de La sombra de un hombre, y Ilamada antiguamente Brentano; el nuevo topónimo conlleva una referencia a Karl Blossfeldt, autor de Urformen der Kunst y representante de la corriente fotográfica de la Neue Sachlichkeit (Nueva Objetividad). Como apunta Miguel Ramalhete Gomes, los planteamientos teóricos de Blossfeldt impregnan el imaginario visual de la ciudad a la que da nombre: "Blossfeldt ficou conhecido por produzir fotografias de plantas tiradas de perto, salientando formas e detalhes ornamentais, e argumentando que tanto a arte como a técnica teriam a aprender com as formas naturais [...]. No universo das Cidades Obscuras, as autoridades na pequena cidade de Brentano empenham-se numa reconstrução total da cidade à imagem das formas fotografadas por Blossfeldt. O entusiasmo é tanto que a cidade muda de nome para Blossfeldtstadt. Todos os edifícios passam a ostentar formas que recordam o leitor do mundo natural" (Ramalhete Gomes 2011: 9-10). 
transporte permanecen anclados en la energía mecánica o a vapor, y en general su nivel de desarrollo tecnológico corresponde al contexto de la segunda revolución industrial, como puede verse en el caso de Mylos. A la vez, como lo exigen los cánones del género, semejante desarrollo ha propiciado un modo de vida bastante más avanzado del que tuvo lugar en el siglo XIX, pues en muchos sitios los desplazamientos se llevan a cabo mediante una red de puentes e intercambiadores a gran altura, cuando no directamente a través del cielo, con zeppelines y globos aerostáticos cuya forma imita la silueta de las aves.

No obstante, la misma etiqueta del steampunk plantea a mi juicio problemas de clasificación genérica, al englobar obras cuya lógica narrativa resulta muy dispar; si nos atenemos a las que se suelen enmarcar bajo su etiqueta ${ }^{25}$, el steampunk acaba quebrando la frontera entre el universo mágico de la fantasy y la lógica causal de la ciencia ficción ${ }^{26}$, mientras que las Ciudades oscuras permanecen ancladas en una civilización mecánica (o que oscila entre esa dicotomía de lo mecánico y lo orgánico), y donde los fenómenos

${ }^{25}$ Me atengo aquí, por su carácter divulgativo, al elenco de la Wikipedia, que coloca bajo el mismo paraguas películas tan dispares como Vidocq, La brújula dorada, La liga de los hombres extraordinarios, Las aventuras de Adèle Blanc-Sec, Wild wild west, El secreto de los hermanos Grimm, Van Helsing o Stardust. Algunas se atienen al modelo genérico, a saber una suerte de "futuro anterior" propiciado por una evolución alternativa de la revolución industrial (Lother 2009: 38-39), pero otras (La brújula dorada o Stardust, por ejemplo) introducen elementos mágicos propios de la fantasy. No se trata de mantener los géneros en compartimentos estancos, algo difícil cuando se trata de narrativas híbridas y fluctuantes, sino de comprender la lógica de lo fantástico en el universo steampunk, que sigue ateniéndose a la lógica de reconstrucción racional de lo incomprensible propia de la ciencia ficción. Por ello, la propia ideología del steampunk nos parece más valiosa para entender el fenómeno que aquello hacia lo que ha derivado su estética, en cuanto atrezzo romántico-futurista, como diagnostica Inés Muñoz Martínez-Mora (2009) en el siguiente artículo de El País:

http://www.elpais.com/articulo/portada/PUNK/SIGLO/XIX/elpepisupep3/20090424e Iptenpor $5 /$ Tes

${ }^{26}$ Para esta diferenciación "clásica" entre géneros, véase Bozzettto (1992: 65): "La science-fiction reconstruit, à partir de traces, une réalité en apparence fondamentalement autre, mais en réalité analogiquement saisissable, dans le cadre d'une série d'extrapolations. On reste dans le domaine de la raison, la résolution de l'énigme la glorifie. [...] Le fantastique, lui, rend évidente l'impossible reconstitution du sens de l'irrationnelle présence des choses. [...] S'il interroge la cohérence de la raison sur ses fondements et ses prétentions, ce n'est pas pour renvoyer à une explication par la 'tradition', mais pour mettre le lecteur en présence d'apories intellectuelles d'une part, et de 'choses sans cause', d'autre part". Esta diferenciación nos muestra que, aquí, la lógica de lo fantástico se inmiscuye en un paradigma epistemológico propio de la ciencia ficción, lo cual responde, de alguna forma, a la disolución de categorías o fronteras a la que tiende un género como el steampunk. Para unos apuntes acerca de lo fantástico en el ámbito del cómic, vid. Lefèvre (2003). 
misteriosos son abordados desde una perspectiva racionalista. En cierto sentido, Schuiten y Peeters convierten dicha perspectiva en una suerte de caricatura impregnada de ironía, convirtiendo así su estética steampunk en una crítica del positivismo industrial, planteada desde el patchwork lúdico de la posmodernidad.

Analicemos el ejemplo de Brüssel, que toma como modelo una ciudad real de nuestro mundo. El álbum comienza con un breve dosier que desgrana algunos de los atropellos urbanísticos cometidos en Bruselas, desde sus anhelos decimonónicos por convertirse en una gran capital europea a la altura de París: el Palacio de Justicia de Polaert, culminación de la más delirante megalomanía finisecular, el recubrimiento del Senne, con lo que la ciudad acaba privándose de su propio río, la confluencia ferroviaria entre las estaciones norte y sur, que arrasa todo el centro durante décadas, la destrucción de su valioso patrimonio Art Nouveau (el caso de Horta), etc.

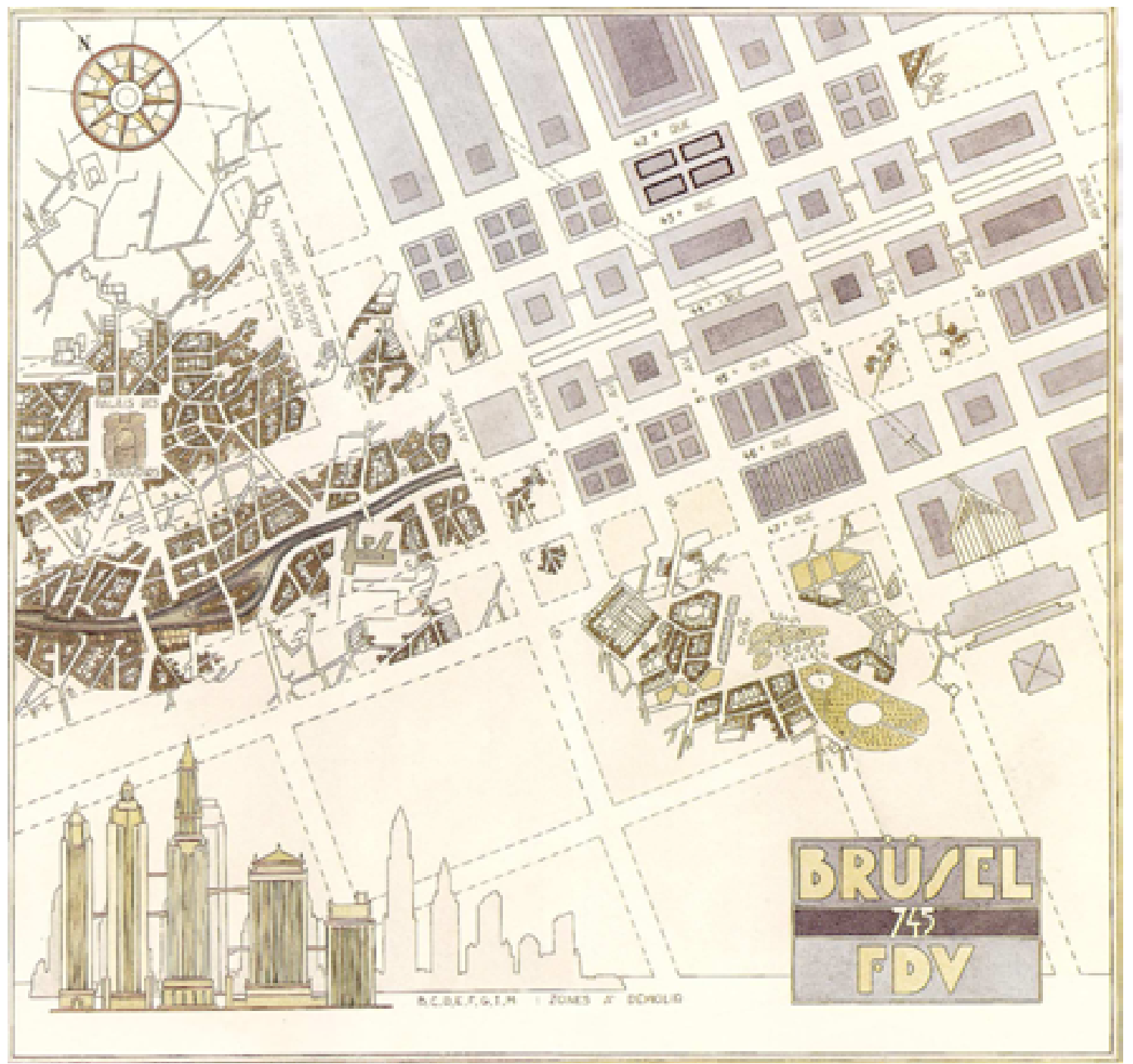

Figura 6. Plano general de Brüssel con su proyecto de desarrollo urbano. 
La historia propiamente dicha se sitúa por su parte en una época que parece corresponderse con la Bruselas anterior a las grandes obras (o destrozos ${ }^{27}$ ). En un viejo barrio de casas flamencas, el florista Abeels Constant se dispone a renovar la totalidad de su negocio con plantas de plástico. Su encuentro con el médico Ernest Dersenval, firme defensor del uso terapéutico de la electricidad (la "dersenvalización"), recalca la entusiasta sintonía de dos espíritus "positivos", partidarios de un progreso que arramble con el presente rancio e inmovilista. La ciudad se halla de hecho en vísperas de una radical transformación; amparado por el burgomaestre, el constructor Freddy de Vrouw se dispone a derribar las zonas viejas y deterioradas para edificar una hilera de rascacielos desproporcionados (figura 7). Semejante obra sume a Brüssel en el más absoluto caos, vacía las arcas públicas, y acaba con una bíblica inundación provocada por la ruptura de los diques que protegen la ciudad (como si estuviera situada en un pólder neerlandés...). El relato finaliza con la huida de los protagonistas en la cabina de un zepelín reconvertida en lancha, y la travesía marítima (el reencuentro con la naturaleza) marca un despertar en el que toman conciencia de haber estado "enfermos de progreso" 28 .

Este relato convierte la historia de una destrucción urbanística real en el apocalipsis de una ciudad completamente imaginaria. Si Brüssel contiene evidentes referencias a Bruselas, como el Palacio de Justicia que se transforma aquí en un castillo kafkiano bautizado como Palacio de los Tres Poderes (nombre de una plaza que se encuentra en Brasilia), la historia se bifurca en un momento dado para convertir Brüssel en la ciudad que Bruselas nunca fue ni llegó a ser. Estos futuros alternativos coinciden no obstante en lo esencial, a saber en las consecuencias de una planificación urbanística absolutamente disparatada.

\footnotetext{
${ }^{27}$ Resulta inevitable equiparar la moraleja de la historia con lo sucedido en nuestra propia ciudad, objeto durante décadas de obras continuas e inacabables, que han arrasado con gran parte de su patrimonio, para acabar protegiendo, en un tardío gesto de arrepentimiento, fachadas aisladas y molduras singulares (lo que Schuiten y Peeters acuñan con el neologismo de "façadisme"). Bruselas y Madrid compartirían así el equívoco encanto de lo derruido, convertido en patrimonio "invisible", y que configuraría una extensa guía urbana de lo que fue y ya no existe. ${ }^{28}$ El final aporta una estructura circular al relato, pues al principio Constant tararea en su tienda la canción de Charles Trenet titulada "El mar", lo que anuncia así la liberación y redención final de los protagonistas en su viaje por el océano.
} 


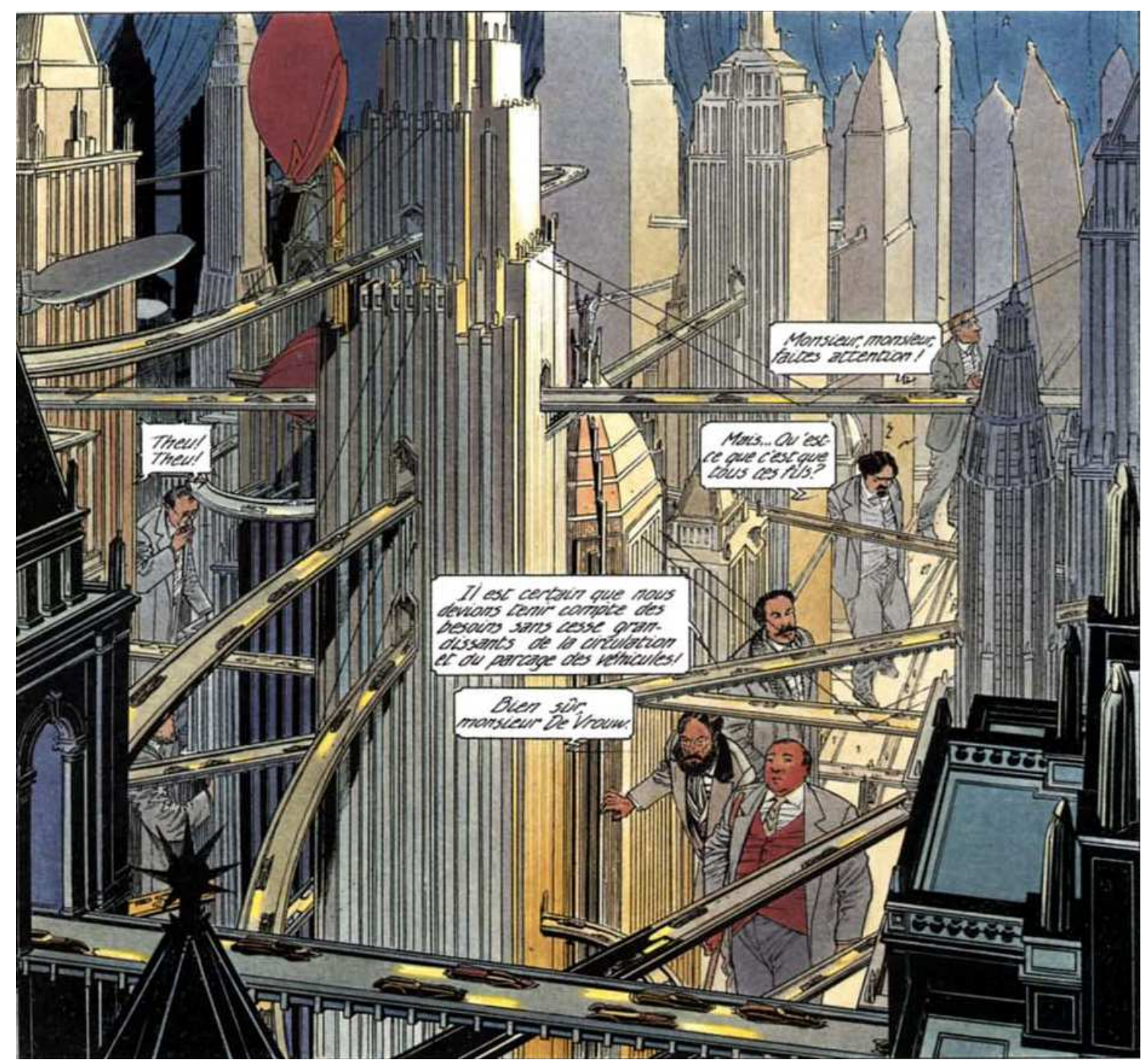

Figura 7. Freddy de Vrouw muestra una maqueta de la futura Brüssel.

Las raíces de estos futuros posibles ha de rastrearse en la fe positiva que impregna buena parte de las Ciudades oscuras, hasta el punto de convertirse en su sustrato ideológico, por así decirlo. Resulta sorprendente que, en un mundo con un carácter tan esotérico y azotado por tantos fenómenos misteriosos, la mayoría de sus personajes manifiesten con tanta firmeza su absoluta confianza y fe en el progreso. La propia Brüssel es buen testigo de ello, con este cataclismo final provocado por "los sueños de la razón", pero indudablemente abunda esta mentalidad imbuida por el espíritu científico, desde Eugen Robick hasta Axel Wappendorf. En La frontera invisible, por ejemplo, la voluntad imperialista de la SodrovnoVoldachie otorga grandes poderes al centro de cartografía, con el fin de establecer el trazado riguroso de una frontera que habrá de legitimar sus pretensiones expansionistas. El conflicto temático del relato se centra en torno al joven Roland de Cremer, que concibe la cartografía como un arte que ha de incorporar la textura y la realidad de los paisajes, e Ismail Djunov, que defiende el uso de las nuevas 
tecnologías como la panacea de la exactitud y la verdad. El motivo "esotérico" aparece aquí en el cuerpo de una prostituta llamada Shkodrâ, que oculta en su espalda una mancha misteriosa, donde Roland cree vislumbrar la enigmática representación de la frontera que ha de acotar y circunscribir: frente a la máquina fría y deshumanizada, la piel del cuerpo se transforma en metáfora para la densidad de un paisaje.

Podrían multiplicarse los casos y citas, pero lo relevante en este caso radica en ubicar esta mentalidad en el contexto histórico donde se desarrollan las ucronías del steampunk: el futuro anterior de una revolución industrial que nunca existió, donde lo fantástico se codea con el desarrollo de la tecnología y -sobre todo- de la ideología científica que lo acompaña. Esta dicotomía, que caracteriza curiosamente el nacimiento de los dos géneros más emblemáticos del siglo XX, a saber la ciencia ficción y la narrativa policíaca ${ }^{29}$, queda de alguna forma revisitada una vez medidos los efectos y las consecuencias de sus planteamientos. Para entendernos, lo que a mi juicio reviste valor en la propuesta estética del steampunk (más allá de una moda para "tunear" máquinas y vestimenta) consiste en retomar esta encrucijada, que marca el nacimiento de la modernidad científica y tecnológica, en el ámbito de la "posmodernidad", o sea al término de su ciclo. Asistimos a un "revival" que nos retroproyecta hacia las raíces de lo que fuimos, midiendo sus consecuencias desde nuestro tiempo (las aberraciones y quimeras como fruto de la dicotomía positivista, entre esoterismo y cientificidad), a partir de las ucronías de un futuro que nunca llegó a ser o, como las califica Miguel Ramalhete Gomes, heterocronías:

We thus have a fracture in our architectural past and a continuous development (in isolation) from that point on. This retro-futurism gives us the concept of another place in another time, a time of heterochronia, a place in a different time-line, and therefore not a simple euchronia. In these stories, the Obscure Cities take place in another world, with a different History and no direct connection to our world.

In this parallel universe based on the juxtaposition of several different cities, criticism (as a defining factor in considering them

29 En sus inicios, la narrativa policíaca supone tanto la aplicación de un método racional de investigación para desentrañar los enigmas de la realidad (el Auguste Dupin de Edgar Allan Poe) como el descartar lo sobrenatural en cuanto explicación de lo incomprensible (mediante esa diferenciación con respecto a lo gótico y lo fantástico que rige la trama de El sabueso de los Baskerville, por ejemplo). De este modo, lo policíaco se cruza con la ciencia ficción en su modo de abordar cuestiones del presente desde una perspectiva ilustrada o positiva, aunque uno parezca centrarse en la realidad urbana decimonónica y la otra las aborde desde proyecciones futuras. 
utopias) is to be understood as criticism of urban planning and of spatial organisation. Social, political and economic issues are usually not addressed in themselves, but almost always as connected to deficient or productive urban planning. We can then say that social conflicts are often expressed as spatial conflicts, in a relation of mise en abyme. This, as we will no doubt notice, is a common feature of these albums. (Ramalhete Gomes 2007: 90-91)

Tal sería el espejo que nos permitiría acotar esta poética temporal y apreciar el carácter visionario de su propuesta visual y narrativa, que trataremos de sintetizar en el colofón del presente artículo.

En primer lugar, este imaginario ucrónico (o heterocrónico) recurre, como ya dejamos entrever, a modelos arquitectónicos soñados o esbozados pero que nunca llegaron a plasmarse. En este sentido, los bocetos de ciudades y edificios proyectados trazan, para cualquier arquitecto, el envés o fundamento que rige y sostiene aquella obra que efectivamente llegó a ver la luz. Las Ciudades oscuras operan así por condensación o amplificación, plasmando ciudades homogéneas que adoptan un único estilo o función (Xhystos y Calvani), o aumentando hasta lo inconcebible la escala y el tamaño de las ciudades contemporáneas (como la Brüssel reconvertida en un futurista Manhattan). Ambas estrategias generan una distorsión que no lleva a reconsiderar o redescubrir aquello que en verdad conocemos, pero que al verse acentuado hasta tal punto provoca igualmente un efecto "futurista por saturación". Así, en La Guía de las Ciudades, vemos referido un misterioso "mal de Xhystos" ${ }^{30}$, nuevo síndrome de Stendhal que aqueja a los transeúntes saturados y desorientados por la profusión ornamental del Art Nouveau.

Pero en numerosas ocasiones, las Ciudades oscuras no se limitan a operar con material ya conocido, sino que se nutren del repertorio de una arquitectura visionaria que ha condicionado a menudo el imaginario utópico de la modernidad. Cabría examinar hasta qué punto reactualizan las figuraciones renacentistas acerca de la "ciudad ideal", que en verdad habrían de conjugarse con la especulación política de Campanella, Bacon o Moro. Los cuadros atribuidos a la escuela de Piero Della Francesca, por ejemplo, son una buena muestra de cómo funciona semejante mecanismo, pues en verdad sus modelos ofrecen una suerte de quintaesencia de tres ciudades "tipo" italianas como son Roma, Florencia o Venecia. De tal modo, el repertorio pictórico que puede calificarse de visionario

30 "L'architecture de Xhystos est, passé le premier émerveillement, d'une extrême monotonie. [...] C'est sans doute ce qui conduit régulièrement des habitants à ne plus pouvoir retrouver le chemin de leur propre habitation et à errer sans fin à travers les rues" (Schuiten \& Peeters 2002: 146). 
extrae sus representaciones de la realidad pero, lo que es más relevante, aspira a construir nuevas formas de la misma ${ }^{31}$. El "vientre" de los arquitectos fecunda, en este mundo paralelo, un repertorio de formas e imágenes que nos proyecta hacia la capacidad visionaria donde lo real se transforma en quimera, y donde la silueta de lo monstruoso late bajo el ideal inmaculado. Las figuras de Etienne-Louis Boullée, como en la película de Peter Greenaway, y de Hugh Ferris, ambos citados en la carta que Eugen Robick envía a la Comisión para reclamar su tercer puente, constituyen ejemplos paradigmáticos de dicho repertorio, cuya influencia cabría rastrear en numerosas viñetas de la serie ${ }^{32}$ (figura 8 ).

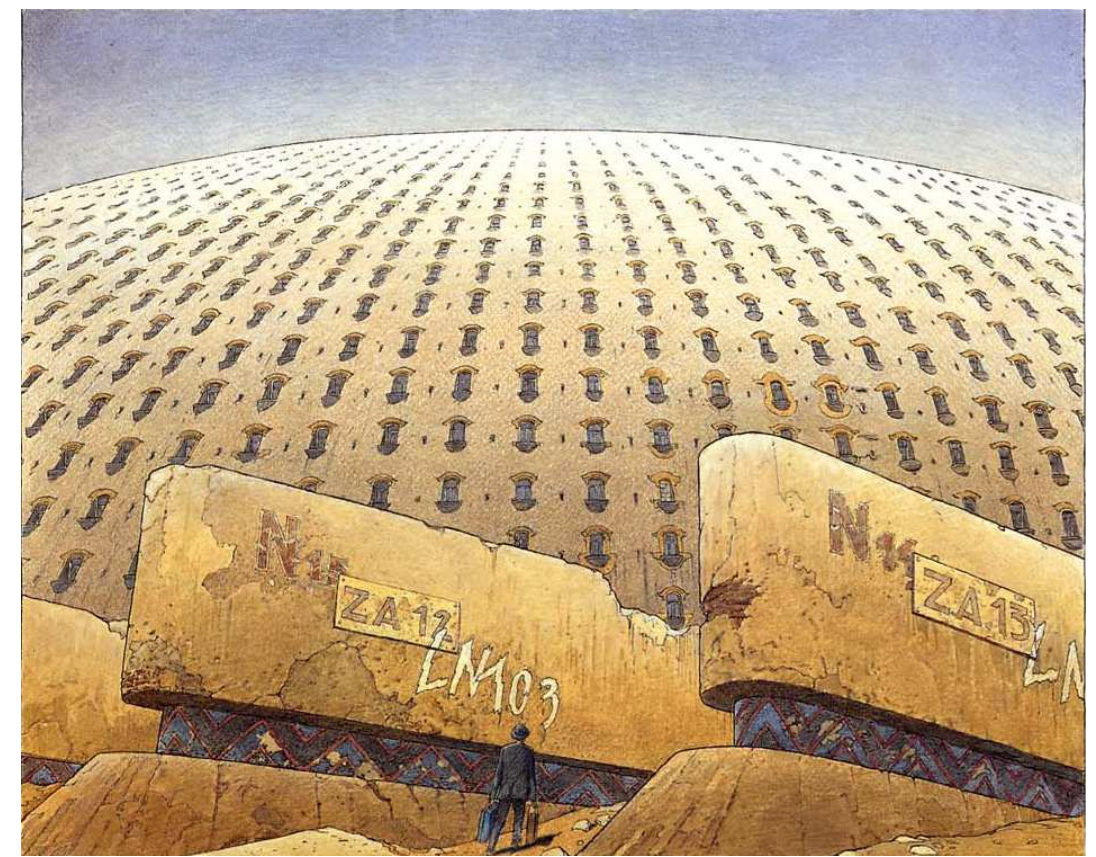

Figura 8. Arquitectura visionaria del Centro de Cartografía en La frontera invisible.

${ }^{31}$ A fin de cuentas, la demarcación entre lo "artístico" y lo "arquitectónico" obedece a la reciente especialización de los saberes, frente a un ideal renacentista que no concebía separación entre pintor y constructor. El estatus ambivalente de la arquitectura y del urbanismo, desde la moderna fractura entre arte y técnica, nos ilustra a fin de cuentas sobre la capacidad performativa del imaginario. De la misma forma que Miguel Ángel pudo llevar a cabo la remodelación del Campidoglio, una reciente exposición sobre Frank Lloyd Wrigth, en el Museo Gugenheim de Bilbao, apenas distinguía, de entre sus numerosos dibujos, aquellos que efectivamente se llevaron a cabo de los que no superaron la mera fase de proyecto, y configuran un nuevo sustrato de "ciudades invisibles", donde atisbamos, por citar un caso, la Bagdad que pudo y nunca llegó a existir.

32 El centro de cartografía donde se desarrolla toda la primera parte de La frontera invisible es una clara adaptación del célebre Cenotafio a Newton, de Boullée. Del mismo modo, los grabados de Ferris inspiran buena parte del carácter monumental de Urbicanda, con un carácter sin duda menos sombrío o contrastado que en el original (al contrario que Gotham City, que suele citarse como ejemplo de la influencia de Ferris en el imaginario popular). 
En segundo lugar, estas innumerables influencias acaban convirtiendo las Ciudades oscuras en un extenso patchwork donde se difuminan las fronteras entre la pura invención y su correspondencia con lo real, en la medida en que pueda establecerse semejante disyuntiva. Ello nos lleva a colocar su imaginario bajo el paraguas algo genérico de la "posmodernidad", cuya acepción conviene explicar y precisar. En efecto, el carácter homogéneo de algunas ciudades no ha de ocultarnos la heterogénea amalgama del conjunto, donde pueden identificarse los más diversos estilos arquitectónicos y urbanísticos. El definir este mundo como "oscuro" no debe interpretarse únicamente en función de los múltiples enigmas 0 fenómenos extraños que allí se producen, y desde luego tampoco se refiere a su carácter tenebroso. En este caso, lo "oscuro" configura un envés de nuestro propio mundo, su historia en negativo, como una sombra alargada que, proyectada en el ámbito de la ficción, nos revela su naturaleza oculta. El dispositivo ficticio condensa los innumerables estratos del tiempo y del espacio, desde un tejido medieval, barroco o bizantino hasta las ciudades orgánicas que aspiran a imitar las formas de la naturaleza, o erigen su verticalidad monumental como un sueño de la razón donde se reactualizaría el mito fundador de Babel. El carácter "posmoderno" radicaría en esta combinación de los diferentes códigos urbanísticos que, situados en un mismo territorio o continente, ofrecen una alternancia de formas y combinaciones, un juego de citas donde la historia de las ciudades no cesa de parodiarse y referirse a sí misma. Esta vertiente lúdica es parte indispensable de su código narrativo (de su revisión "posmoderna"), y el caso de Brüssel supondría tal vez uno de sus mayores divertimentos (con el sueño de Dersenval por sustituir la naturaleza con plantas de plástico, y sus terapias eléctricas que por un error de reglaje le sumirán en la más profunda afasia). Existe una indudable voluntad "paródica", una sorprendente conjunción entre el realismo, el humor y lo insólito (el umheimlich), sobre la que incide Jan Baetens en su entrevista a Benoît Peeters (Baetens 2001: 51).

De forma paralela, asoma bajo este mosaico de estilos y referencias una fuerte presencia de las ruinas, como si el frágil equilibrio de las ciudades se sostuviera sobre la constante amenaza de su desaparición, erigiendo en la ruina la huella y el emblema de su carácter transitorio ${ }^{33}$. Hallamos a lo largo del ciclo numerosas referencias a destrucciones y cataclismos. Pensemos que la Torre, como mito fundador, vive bajo la constante amenaza de su

${ }^{33}$ El estudio de referencia es aquí el de Ramalhete Gomes (2011), que analiza esta representación de las ruinas bajo la perspectiva de una "historia natural", tal y como la conciben T. W. Adorno y Walter Benjamin, y que se centra en el análisis de Souvenirs de l'éternel présent, sin duda uno de los álbumes conceptualmente más sugerentes hasta la fecha. 
derrumbe. Los casos de Brüssel o Urbicanda nos ofrecen asimismo una suerte de "historia natural de la destrucción", por voluntad política (la ambición de Freddy De Vrouw) o proliferación misteriosa del "réseau". Los alrededores de Pahry albergan incluso, en los restos de una Exposición Interurbana celebrada en 751, un laberinto de ruinas cercano al desierto de los Somonitas, vestigios prefabricados convertidos en atracción para turistas.

A mi juicio, los dos motivos más emblemáticos de lo que en las Ciudades oscuras configura un "mosaico de ruinas" se encuentran en La frontera invisible y en la última entrega, Recuerdos del eterno presente. En el primero, Paul Ciceri ("Monsieur Paul"), maestro y jefe de Roland de Crémer, le somete en su encuentro inicial a un análisis cartográfico de fotografías que se transforma en una auténtica hermenéutica de las ruinas, donde el joven aprendiz ha de interpretar lo que ve en función de sus rastros, convirtiendo el significado del espacio en una lectura de los estratos del tiempo. Esta lección se antojará decisiva; frente a la voluntad imperialista de la SodrovnoVoldachie, que falsifica sus fronteras para legitimar una conquista, Roland de Crémer emprende junto con Skohdrâ una huida que se convertirá en un viaje a través de las ruinas de un territorio asolado por el gigantesco muro de una frontera erigida por los vencedores. La destrucción y la barbarie asoman en las magras huellas de lo que todavía subsiste, donde la desaparición misma cobra existencia y se muestra en cuanto naturaleza extinta.

Recuerdos del eterno presente podría constituir el colofón de los sucesivos apocalipsis que se ciernen sobre las Ciudades oscuras. En un lugar sumido en la devastación, y que ha renunciado al progreso (a la "fe positiva") debido a sus funestas consecuencias, reina el "eterno presente". Toda tecnología ha sido proscrita y la memoria del pasado eliminada por decreto. No caben preguntas sobre lo que fue ni sobre las causas de lo que sucedió; el anhelo y la nostalgia de un tiempo inmóvil parecen oponerse aquí a las quimeras fallidas de la historia (que en este caso se cifró en lograr una réplica perfecta -una clonación- de sí misma). Solamente un niño, desde su curiosidad innata y sus preguntas obstinadas, procura averiguar las razones del cataclismo. Su frustrado peregrinaje le conduce por un elenco de los hitos de nuestra civilización, transformados en absurdos y derruidos vestigios de una gloria pasada (figura 9). 


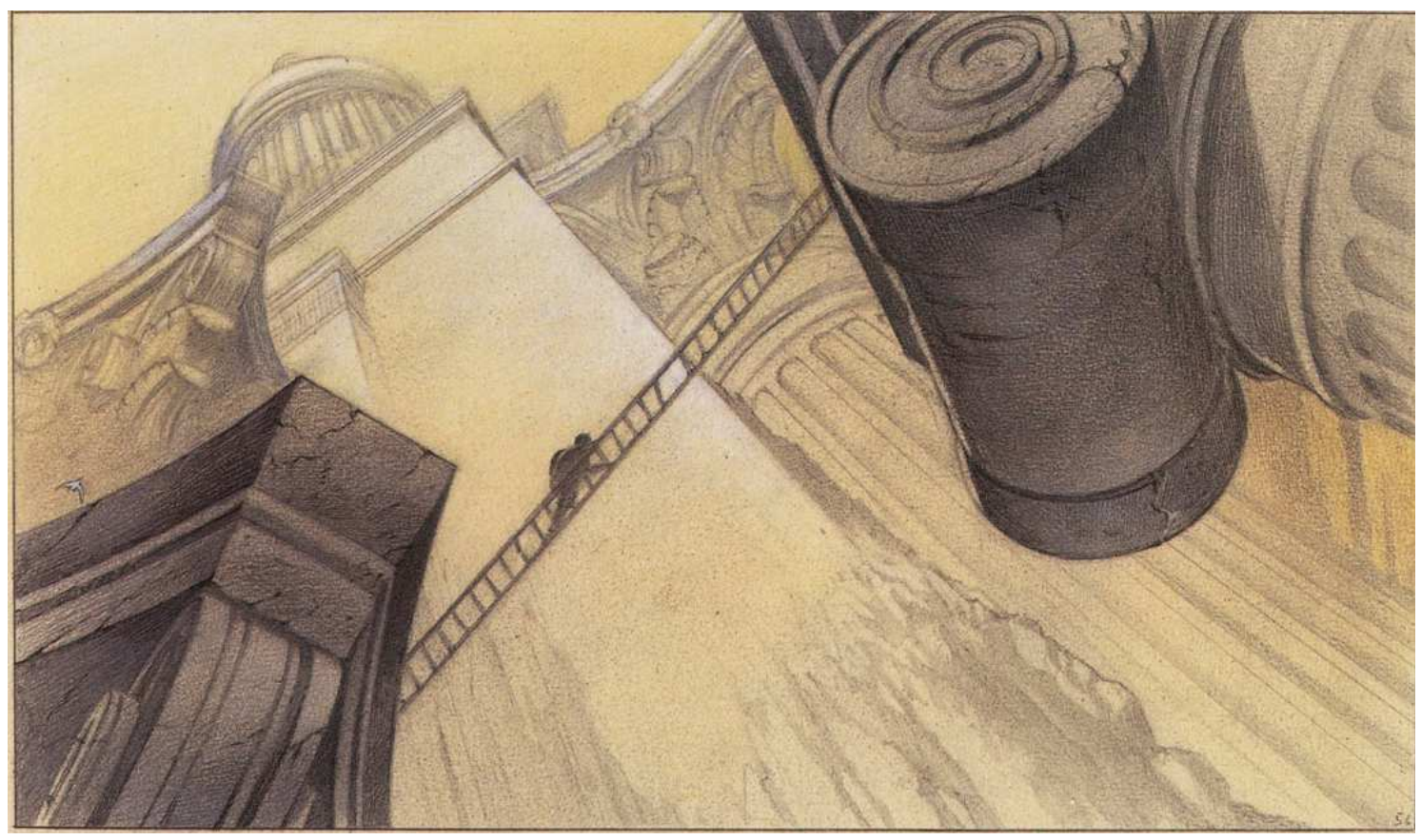

Figura 9. El mosaico de ruinas en Recuerdos del eterno presente.

La capacidad sincrética de Schuiten y Peeters abarca los más diversos estratos de la devastación, desde las catedrales góticas hasta la majestuosa solemnidad de los palacios y escalinatas decimonónicos. Grandiosas esculturas neoclásicas alternan con los lugares emblemáticos del turismo finisecular, en una visión final del mar que parece inspirarse en Los 400 golpes de Truffaut, donde la chatarra y los buques encallados se juntan con los grandes hoteles que evocan el Deauville de la costa normanda. Y como lugar común de nuestra relectura del pasado a través de sus ruinas, emerge el estilo que envuelve y domina el conjunto, una reelaboración de la arquitectura greco-latina, donde la mezcla de columnas corintias, frontones y cúpulas se amontona hasta formar una gigantesca torre en el que yacen las momias de los antiguos gobernantes y las respuestas se convierten en simulacro, como en el caso de Samaris.

Este patchwork de ruinas y estilos nos lleva a acotar, para concluir, el mecanismo de irrupción de lo fantástico en el ámbito de las Ciudades oscuras, envuelto en la fe positiva de una heterocronía con una marcada raigambre steampunk. Para decirlo en pocas palabras: dicha irrupción de lo fantástico corresponde a una perturbación del equilibrio urbano que provoca la desubicación del individuo. Si nos atenemos a los casos mencionados en nuestro artículo, podemos constatar fácilmente que los personajes del ciclo quedan privados de su capacidad para orientarse en su propio mundo. Cabe referirse a Giovanni Battista, en su largo errar por una Torre sin fin cuya cima solo le muestra el vacío celeste; a Franz Bauer, perdido entre la realidad y el simulacro de una ciudad concebida como decorado; a Eugen Robick, que asiste perplejo al 
crecimiento misterioso del "réseau" que sume Urbicanda en un caos alegre y febril; a Abeels Constant, que contempla impotente la destrucción de su antiguo barrio; a Mary Von Rathen, arrastrada por culpa de su "enfermedad" a convertirse en animal circense; al Albert Chamisso de La sombra de un hombre (otro guiño, esta vez al autor de Peter Schlemih/), condenado a un destino semejante al de Mary, etc.

Todos los personajes padecen algún tipo de anomalía o de marginación social; frente a la dimensión central de la urbe en los relatos, sus protagonistas quedan descentrados, abocados al extravío, la locura o la errancia. Mas sus peripecias se ven directamente conectadas con la encrucijada conflictual de lo urbano entre orden y caos, realidad y apariencia; en suma, por el desajuste de una armonía quebrada e inalcanzable. Como afirma Michela De Domenico:

The city is the core element of these stories, seen as an utopian and abstract principle, as well as a machine in which man becomes marginal, annihilated as a puppet. The architecture, indifferent to man and memories, is obsessively repeated and the city selfgenerates its clones. (De Domenico 2011: 242)

La problemática de lo individual frente a lo colectivo se inscribe así en la tradición distópica de la ciencia ficción, pero no se trata, podríamos decir, de pesadillas totalitarias al uso, sino más bien de una quiebra o "fiebre" que arrastra el individuo a sentirse extranjero o desplazado con respecto al entorno que habita. Pero, al mismo tiempo, tales individuos luchan por encontrar un espacio propio en su condición exiliada, por hallar, siguiendo la parábola de Mary Von Rathen, la órbita a la que pertenecen. Incluso en los finales más desesperanzados, permanece abierto el horizonte de una nueva fundación, entornada la puerta que nos invita a un nuevo viaje.

En consecuencia, si las Ciudades oscuras trazan un recorrido por los estratos temporales de la arquitectura y el urbanismo modernos, su conflicto narrativo se centra en la relación del hombre con lo que, tal vez, constituya la manifestación más emblemática de su civilización y su desarrollo. Pero cuando la ciudad ideal o deseada no queda muy lejos de la ciudad infernal, subsisten los intersticios donde procuramos asentar nuestras frágiles redes de convivencia. A la sombra de calles y edificios, miramos hacia el horizonte de este "mundo oscuro" donde se reflejan nuestras pulsiones y traumas, tejiendo una suerte de no lugar en el espacio de lo ficticio que alberga, en su espejo, la advertencia de un peligro y la ensoñación de lo posible. Como dice Marc Augé: 
Necesitamos una utopía de la educación y de la ciencia que nos permita pensar que el porvenir del conocimiento es el porvenir de toda la humanidad, y no el de una minoría rica, ilustrada y dominante. El espacio de esa utopía lo poseemos ya: es el planeta. Y sus construcciones más significativas (las singularidades y los no lugares) son el espacio virtual de esta utopía: lo que les falta, hoy, es que logre apropiárselos una humanidad sin fronteras. Los no lugares poseen la belleza de lo que habría podido ser. De lo que aún no es. De lo que, un día, tal vez, tenga lugar. (Augé 2008: 158)

\section{Bibliografía}

AUGÉ, Marc (2008): El tiempo en ruinas. Barcelona: Gedisa.

BAETENS, Jan; \& PEETERS, Benoît (2001): "Entretien avec Benoît Peeters" [en línea]. Image \& Narrative. Online Magazine of the Visual Narrative, vol. 1, september, (issue 2.2), ISSN: 1780-678X. En:

http://www.imageandnarrative.be/inarchive/fantastiquebd/baetenspe eters.htm [Consulta: 01/10/2011].

BLANQUART, Paul (1997): Une histoire de la ville (Pour repenser la société). Paris: La Découverte.

BOZZETTO, Roger (1992): L'obscur objet d'un savoir. Fantastique et science-fiction: deux littératures de l'imaginaire. Aix-en-Provence: Publications de I'Université de Provence.

CALVINO, Italo (1983): Las ciudades invisibles. Barcelona: Minotauro.

CHOAY, Françoise (1979): L'urbanisme, utopies et réalités (Une anthologie). Paris: Seuil.

DE DOMENICO, Michela (2011): "Utopy and comics imaginary cities" [en línea], in Proceedings Conference My Ideal City. Scenarios for the European Cities of the 3rd Millenium (Università Iuav di Venezia, 2223 de mayo), pp. 238-246. En:

http://docu.iuav.it/99/1/My Ideal City De Domenico, Michela.pdf [Consulta: 15/09/2011].

DETHIER, Jean; \& GUIHEUX, Alain (coords.) (1994): La ville, art et architecture en Europe, 1870-1993. Paris: Éditions du Centre Pompidou.

FLAUBERT, Gustave (1999): Salambó. Madrid: Edaf.

GERBIER, Laurent (2003): "Découpage fantastique et continuité graphique dans la bande dessinée", en Otrante. Art et littérature fantastique (Fantastique et bande dessinée), núm. 13, pp. 21-28. Paris: Kimé.

LEFÈVRE, Pascal (2003): "Le fantastique, un genre indéfinissable?", en Otrante. Art et littérature fantastique (Fantastique et bande dessinée), núm. 13, pp. 13-20. Paris: Kimé.

LOTHER, Sébastien (2009): Steampunk. Rencontre entre l'architecture et le 9ème Art [en línea]. Tesina de Master 2 del Institut Supérieur d'Architecture Saint-Luc de Liège (dir. de Marie Roosen y Luc Lejeune).

http://membres.multimania.fr/sypurk/memoiresteampunkBQ.pdf [Consulta: 21/09/2011]. 
MARION, Philippe (1997): "Narratologie médiatique et médiagénie des récits" [en línea]. Recherches en communication, num. 7, pp. 61-87. En:

http://sitestest.uclouvain.be/rec/index.php/rec/article/viewFile/1441/1291 [Consulta: 12/10/2011].

McCLOUD, Scott (2007): Entender el Cómic: El arte invisible. Bilbao: Astiberri.

MERLIN, Pierre (1991): L'urbanisme. Paris: Presses Universitaires de France.

MUÑOZ MARTÍNEZ-MORA, Inés (2009): "Punk del siglo XIX" [en línea]. El País, 24 de abril de 2009. En: http://www.elpais.com/articulo/portada/PUNK/SIGLO/XIX/elpepisupe p3/20090424elptenpor 5/Tes

RAGON, Michel (2010): Histoire de l'architecture et de l'urbanisme modernes, 3 vols. Paris: Seuil.

RAMALHETE GOMES, Miguel (2007): "The City and the Plan: Schuiten and Peeters's Graphic Meta-Utopias" [en línea]. Spaces of Utopia: An Electronic Journal, núm. 4 (Spring), pp. 88-105. En: http://ler.letras.up.pt/uploads/ficheiros/3902.pdf [Consulta: 29/09/2011].

RAMALHETE GOMES, Miguel (2011): "Uma História Natural da Utopia: O Caso das Cidades Obscuras" [en línea]. E-topia: Revista Electrónica da Estudos sobre a Utopia, núm. 12, ISSN: 1645-958X. En: http://ler.letras.up.pt/uploads/ficheiros/8908.pdf [Consulta: 29/09/2011].

RIBERI, Alejandro (2010): "The construction of fantastic spaces: Tlön, Les Cités Obscures and the cognitive power of fiction" [en línea]. Lejana. Revista crítica de narrative breve, núm. 1, pp. 1-8. En: http://lejana.elte.hu/PDF cikkek/Alejandro Riberi art.pdf [Consulta: 27/07/2011].

SCHUITEN, François; \& PEETERS, Benoît (1996): L'aventure des images. De la bande dessinée au multimédia. Paris: Autrement, coll. Mutations, núm. 167.

STEIMBERG, Alejo (2004a): "Les cités obscures de Schuiten et Peeters: analyse d'un dispositif fantastique transmédiatique". Cuadernos de Filología Francesa, vol. 16, pp. 207-221.

STEIMBERG, Alejo G. (2004b): "Fantastique et bande dessinée: le domaine de l'invisible. Une lecture de La fièvre d'Urbicande, de Schuiten et Peeters" [en línea]. Revue des Littératures de I'Union Européenne, Numéro Spécial DESE 1, ISSN: 1827-7047. En: http://www.rilune.org/dese/tesinepdf/Steinberg/Steinberg Artfantast ique.pdf [Consulta: 28/08/2011].

STEIMBERG, Alejo G. (2004c): "Les œuvres en hypertexte et hypermédia: quelques notions théoriques. Le cas d'Urbicande.be" [en línea]. Revue des Littératures de I'Union Européenne, Numéro Spécial DESE 1. En: http://www.rilune.org/dese/tesinepdf/Steinberg/Steimberg Litt\%E9r atureetinformatique.pdf [Consulta: 28/08/2011]. 


\section{Las ciudades oscuras ${ }^{34}$ Corpus central:}

Les murailles de Samaris (1983, reed. 2007)

La fièvre d'Urbicande (1985, reed. 2009)

La Tour (1987, reed. 2008)

L'archiviste (1987, reed. 2009)

La route d'Armilia (1988, reed. 2010)

Brüssel (1992, reed. 2008)

L'enfant penchée (1996, reed. 2010)

L'ombre d'un homme (1999, reed. 2009)

La frontière invisible, t. 1 et 2 (2002, 2004, reed. íntegra 2006)

La théorie du grain de sable, t. 1 et $2(2007,2008)$

Souvenirs de l'Éternel présent (2009)

\section{Corpus periférico:}

Le Mystère d'Urbicande (1985)

L'Encyclopédie des transports présents et à venir (1988)

Le musée A. Desombres (1990)

Souvenirs de l'Éternel présent (1993)

L'Écho des Cités (1993)

Mary la penchée (1995)

Le Guide des Cités (1996, reeds. 2002 y 2011)

Voyages en Utopie (2000)

L'étrange cas du docteur Abraham (2001)

L'Affaire Desombres (DVD, 2002)

Les Portes du Possible (2005)

34 Indicamos la fecha original de edición y la de reedición, que en numerosas ocasiones incluye variaciones y nuevos aportes. La fecha incluida en las citas del artículo, con el apellido de ambos autores, corresponde a la reedición (reed.) cuando nos ha sido posible acceder a ella. Aunque mencionemos el título traducido al español, hemos tomado en cuenta el original en francés para la referencia bibliográfica. La distinción entre corpus central y periférico, pese a obviar el hecho de que cada publicación es parte indisociable de una configuración global, procura distinguir aquellas obras donde se encuentra un hilo narrativo evidente de las otras que de alguna forma complementan el conocimiento y la exploración del mundo oscuro. Un catálogo exhaustivo puede consultarse en:

http://www.bedetheque.com/serie-414-BD-Cites-obscures.html.

Existen además una serie de páginas web indispensables para adentrarse en las Ciudades oscuras que son http://www.ebbs.net/, http://www.altaplana.be/start, http://citesobscures.free.fr/ y la primera de todas (1996), aunque algo desactualizada: http://www.urbicande.be/. 